\title{
Effects of transcranial magnetic stimulation on neurobiological changes in Alzheimer's disease (Review)
}

\author{
SHAHID BASHIR ${ }^{1}$, MOHAMMAD UZAIR $^{2}$, TURKI ABUALAIT ${ }^{3}$, MUHAMMAD ARSHAD $^{2}$, \\ ROAA A. KHALLAF ${ }^{1}$, ASIM NIAZ ${ }^{1}$, ZIYAD THANI ${ }^{1}$, WOO-KYOUNG YOO ${ }^{4}$, ISAAC TÚNEZ ${ }^{5,6}$, \\ ASLI DEMIRTAS-TATLIDEDE ${ }^{7}$ and SULTAN AYOUB MEO $^{8}$
}

\author{
${ }^{1}$ Neuroscience Center, King Fahad Specialist Hospital Dammam, Dammam, Eastern Province 32253, Saudi Arabia; \\ ${ }^{2}$ Department of Biological Sciences, Faculty of Basic and Applied Sciences, International Islamic University Islamabad, \\ Islamabad 44000, Pakistan; ${ }^{3}$ College of Applied Medical Sciences, Imam Abdulrahman Bin Faisal University, \\ Dammam, Eastern Province 34212, Saudi Arabia; ${ }^{4}$ Department of Physical Medicine and Rehabilitation, Hallym University \\ College of Medicine, Anyang, Gyeonggi-do 24252, Republic of Korea; ${ }^{5}$ Department of Biochemistry and Molecular Biology, \\ Faculty of Medicine and Nursing/ Instituto Maimónides de Investigación Biomédica de Córdoba (IMIBIC), \\ University of Cordoba, Cordoba 14071; ${ }^{6}$ Cooperative Research Thematic Excellent Network \\ on Brain Stimulation (REDESTIM), Ministry for Economy, Industry and Competitiveness, 28046 Madrid, Spain; \\ ${ }^{7}$ Department of Neurology, Bahcesehir University School of Medicine, Istanbul 34734, Turkey; \\ ${ }^{8}$ Department of Physiology, College of Medicine, King Saud University, Riyadh 11451, Saudi Arabia
}

Received September 15, 2021; Accepted December 15, 2021

DOI: $10.3892 / \mathrm{mmr} .2022 .12625$

\begin{abstract}
Alzheimer's disease (AD) is a neurodegenerative disorder characterized by cognitive decline and brain neuronal loss. A pioneering field of research in AD is brain stimulation via electromagnetic fields (EMFs), which may produce clinical benefits. Noninvasive brain stimulation techniques, such as transcranial magnetic stimulation (TMS), have been developed to treat neurological and psychiatric disorders. The purpose of the present review is to identify neurobiological changes, including inflammatory, neurodegenerative, apoptotic, neuroprotective and genetic changes, which are associated with repetitive TMS (rTMS) treatment in patients with AD. Furthermore, it aims to evaluate the effect of TMS treatment in patients with AD and to identify the associated mechanisms. The present review highlights the changes in inflammatory and apoptotic mechanisms, mitochondrial enzymatic activities, and modulation of gene expression (microRNA expression profiles) associated with rTMS or sham procedures. At the molecular level, it has been suggested that EMFs generated by TMS may affect the cell redox status and amyloidogenic processes. TMS may also modulate gene expression by acting on both transcriptional and post-transcriptional regulatory
\end{abstract}

Correspondence to: Dr Shahid Bashir, Neuroscience Center, King Fahad Specialist Hospital Dammam, Ammar Bin Thabit St, Al Merikbat, Dammam, Eastern Province 32253, Saudi Arabia E-mail: shahidbpk13@gmail.com

Key words: Alzheimer's disease, brain stimulation, transcranial magnetic stimulation, biomarker, neurobiology mechanisms. TMS may increase brain cortical excitability, induce specific potentiation phenomena, and promote synaptic plasticity and recovery of impaired functions; thus, it may re-establish cognitive performance in patients with AD.
Contents
1. Introduction
2. TMS
3. AD and NIBS by TMS
4. Neurobiological changes associated with TMS in AD
5. Potential side effects associated with TMS treatment
6. Discussion
7. Conclusion

\section{Introduction}

Alzheimer's disease (AD) is the most frequent, heterogeneous and severe form of dementia; it is characterized by chronic, gradual and progressive memory loss, and a decline in two or more cognitive functions. The clinical hallmarks of AD include memory deficits and the associated deterioration of attention, executive function, cognitive ability and behavioral abilities. AD is a progressive and complex neurodegenerative disorder, which eventually causes social or occupational impairment (1-3). In 2020, AD accounted for $60-80 \%$ of all dementia cases out of the 50 million patients with dementia worldwide (4). The literature has demonstrated that the neuroand histopathological hallmarks expressively include the buildup of extracellular amyloid- $\beta$ (A $\beta$ ) peptides as amyloid plaques and intracellular aggregates of hyperphosphorylated 
tau protein in the form of neurofibrillary tangles, which disturb microtubule organization and cholinergic dysfunction $(3,5)$. Furthermore, granulovacuolar degeneration (6), neuroinflammation (7), oxidative stress (8), reactive oxygen species (ROS) (9), glutamate dyshomeostasis (10), immunosenescence (11), aggregation of misfolded proteins (12), and mitochondrial oxidative and nitrosative stress (13) also affect the central nervous system, promoting neural dysfunction and synaptic loss, thus leading to increased vulnerability to neuronal degeneration and cell death in AD (6-12). In addition, aging remains a major pathological risk factor for AD (14). These clinicopathological entities ultimately lead to neurodegeneration, synaptic dysfunction, hippocampal degeneration and atrophy, thus culminating in memory, cognitive and functional decline (10,15-17).

Researchers have been increasingly interested in examining reliable novel imaging techniques [i.e., functional magnetic resonance imaging (fMRI) and positron emission tomography (PET)] (18) and in vivo biomarkers (such as $\beta$-amyloid and tau protein) (19) involved in the various pathologies of $\mathrm{AD}$, and numerous molecular marker tests $[\mathrm{A} \beta$ positron emission tomography (PET), cerebrospinal fluid (CSF) total or phosphorylated tau and tau PET)] (19) have been developed to detect such pathologies. The outcomes of neuro-imaging technique and blood-based biomarkers will be important in identifying the molecular mechanisms and pathological pathways responsible for the neurodegenerative progression and development of AD. Since A $\beta$ peptides and phosphorylated tau proteins are highly present in AD, these molecules are considered to be biomarkers that can be used for the neurochemical diagnosis of AD (20). The cerebrospinal fluid concentration, and blood and plasma levels of $A \beta$ and phosphorylated tau are the most accurate biological markers for diagnosing AD (21-23).

Over the past few decades, there has been increasing interest in biological markers to understand and diagnose AD via imaging techniques. The application of neuroimaging biomarkers has become a standard tool for understanding the preclinical stages of AD and for periodic follow-up, as well as for diagnosing AD (24). Various neuroimaging biomarkers, including amyloid positron emission tomography imaging (25), MRI (26) and optical coherence tomography (27), have been used for the diagnosis of AD. Over the past two decades, noninvasive brain stimulation (NIBS) with electromagnetic fields (EMFs) has received much interest regarding neuropsychiatric disorders, and this research area has progressed greatly (28). Among the NIBS techniques, transcranial magnetic stimulation (TMS) has emerged as a potential method providing a promising avenue to treat cognitive impairment, such as AD $(2,29)$. A number of experimental studies on animal models and clinical trials have demonstrated the beneficial therapeutic effects of TMS on neurodegenerative disorders $(30,31)$, including AD $(32,33)$. Increasing evidence indicates that TMS treatment permits the neurophysiological (including motor cortex and neuronal activities) $(34,35)$ and neurochemical (BDNF, TrkB) $(36,37)$ functions to work more precisely, and TMS also regulates biomarkers level and further improves the accurate and precise functioning of neurons in AD (Fig. 1). In addition, research suggests that TMS improves neural branching, cortical excitability and cognitive processes in AD (38). Repetitive TMS (rTMS) provides a safe and noninvasive technique, which modulates cortical excitability, neurochemical functions and neuronal polarization $(39,40)$. However, to the best of our knowledge, the precise molecular mechanism behind the neurorestorative effects of TMS is not yet fully understood. The neurological changes, including inflammatory, neurodegenerative, apoptotic, neuroprotective and genetic changes, during and after TMS treatment in patients with AD are also not precisely known. The present review focuses on TMS and rTMS, as an efficient technique, giving an overview of the changes in inflammatory and apoptotic mechanisms, mitochondrial and enzymatic activities, and modulation of gene expression [or microRNA (miRNA/miR) expression profiles] in patients with AD. The present review also examines the clinical and neurochemical changes associated with rTMS in patients with AD.

\section{TMS}

NIBS techniques are emerging and revolutionizing neuroscience research. NIBS, particularly by EMFs, allows the study of the relationship between the brain and certain behaviors. NIBS techniques include TMS, transcranial direct current stimulation and electroconvulsive therapy $(39,41)$. TMS is a well-known neurophysiological NIBS technique that was first introduced in 1985 (42). NIBS using TMS does not require any surgery, anesthetic agents, skin preparation or intravenous systems, and it is a painless technique (43), and thus, is rapidly becoming an efficient therapeutic tool in cognitive neuroscience research. At present, TMS is a Food and Drug Administration (FDA)-approved therapy for treating major depressive disorder $(44,45)$, treatment-resistant obsessive-compulsive disorder (46) and migraine headaches (47). However, a number of animal models and clinical trials have demonstrated promising results in treating cognitive and neurodegenerative disorders $(43)$, including $\operatorname{AD}(48,49)$ and Parkinson's disease $(30,50,51)$. It has been suggested that TMS could be used to treat between 70 and $80 \%$ of AD cases (52). The therapeutic value of TMS may be achieved by applying EMFs to the predetermined cortical target based on Faraday's principle of electromagnetic induction, which was established in the latter half of the nineteenth century (53). It involves the application of time-varying MRI-strength magnetic fields near the scalp and superficial layer of the cerebral cortex, inducing focal electric currents, known as 'Eddy currents', which run in the opposite direction to the current in the coil and generate a magnetic field that induces currents $(54,55)$. When the stimulation of the magnetic coil occurs tangentially near the M1 region, an appropriately strong stimulus is administered, and the powerful magnetic field penetrates the scalp and skull, where it activates underlying neurons and synapses, depolarizing axons in the targeted brain areas, and thus, stimulating the brain region (56-58).

Types of TMS. TMS can be applied either in single pulses of stimulation [single-pulse TMS (sTMS)], pairs of stimuli [paired-pulse TMS (ppTMS)] separated by variable intervals [interstimulus interval (ISI)] or trains of repetitive stimuli (rTMS) that repeatedly pulse the EMFs at variable frequencies applied to the brain regions (59). 
sTMS is used to map cortico-motor outputs and assess central motor conduction time, motor-evoked potential (MEP) and motor cortical outputs. sTMS is delivered in single pulses of stimulation that are separated by time intervals of 4-8 sec (59).

ppTMS, which runs alternate to conventional TMS, is used to measure intracortical facilitation, cortico-cortical connection excitability, motor cortex connectivity (inhibition and facilitation) and motor cortical pathways. ppTMS utilizes two successive pulse stimuli, conditioning the stimulus with a test stimulus that is separated by an ISI. A short ISI lasts for a few milliseconds, and a long ISI ranges between tens and hundreds of milliseconds $(54,59,60)$.

rTMS has gained much interest from neuroscientists due to its positive effects on cognitive tasks, and behavioral and normal brain functioning (61). rTMS induces trains of electric currents to the predetermined brain region that are delivered through pulsating magnetic fields with a time interval of a maximum of $2 \mathrm{sec}$ (54). High-frequency rTMS (HF-rTMS; $10-20 \mathrm{~Hz}$ ) tends to increase cortical excitability, intercellular interactions and MEP amplitude. Low-frequency rTMS (LF-rTMS; $1-5 \mathrm{~Hz}$ ) reduces cortical excitability and MEP amplitude (62). HF-rTMS and LF-rTMS have opposite effects on brain regions but both have potential therapeutic effects. It has been suggested that rTMS exerts long-lasting effects on cortical excitability and plasticity $(59,63)$.

TMS is a widely accepted and well-established technique allowing for the assessment and modulation of neural excitability and neuroplasticity of pre-specified brain regions. TMS is an effective and promising neuromodulation treatment, as it enhances the functional recovery of cortical and neural function (64). At the molecular level, it has been proposed that TMS modifies neural excitability, the functional integrity of neural circuits, neuroplasticity, synapses and normal brain activity (43). TMS-evoked therapeutic effects can spread to the interconnected cortical region, subcortical structures, spinal cord and roots (59). TMS could potentially be used to treat neurological disorders, including AD; however, the underlying cellular processes and mechanisms of its therapeutic effects are still not clearly understood.

\section{AD and NIBS by TMS}

$\mathrm{AD}$ is a neurodegenerative disorder that is characterized by cognitive decline and brain neuronal loss of an unknown etiology. Early studies have provided a basic and molecular understanding the pathogenesis of AD $(1,65)$. AD neuropathology is considered to be commonly associated with altered neuroplasticity, neurotrophic impairment, neurotransmitter failure and synaptic loss. Furthermore, synaptic dysfunction is noted in the early stages of AD and has become a therapeutic target for pharmaceutical agents $(1,65)$. However, more research is required to clarify the pathogenesis of $\mathrm{AD}$. A pioneering field of research in $\mathrm{AD}$ is brain stimulation via EMFs, which may have clinical and therapeutic benefits. Numerous studies and a few clinical trials have demonstrated the potential therapeutic effects of NIBS, particularly TMS, on patients with $\mathrm{AD}(2,36,66)$. Due to the ageing process, the cognitive decline and deterioration of neural plasticity occurs, which may worsens by MCI or AD. However, TMS improves cognitive ability and increases neural plasticity. Therefore, NIBS techniques exerts a neuroprotective effect on AD (Fig. 2). Although TMS treatment is approved by the FDA for depression (44), it is still an experimental therapy for AD. Extensive research has indicated that TMS might be an effective treatment for patients with AD $(67,68)$. TMS promote synapses, neurogenesis and normal brain functioning stability that aid in the treatment of AD (63). To the best of our knowledge, the basic mechanism behind the neurorestorative effects of treatment with EMFs in patients with AD is still elusive. Furthermore, the neurological and neurochemical changes during and after TMS treatment in patients with AD are not clearly explained. Previous studies have suggested that changes in inflammatory and apoptotic mechanisms, mitochondrial enzymatic activities, and modulation of gene expression (miRNA expression profiles) may be associated with TMS or sham procedures $(69,70)$.

\section{Neurobiological changes associated with TMS in AD}

The present review identifies neurobiological changes, including the inflammatory, neurodegenerative, apoptotic, neuroprotective and genetic changes, associated with TMS treatment in patients with AD.

Neural restoration by TMS. Neurotrophic factors (NTFs) regulate the growth, survival, proliferation, migration and differentiation of neurons (71). Therefore, NTFs have been extensively studied in the context of neurodegenerative disorders, including AD (72). In AD, the altered expression and gradual dysregulation of NTFs, such as nerve growth factor (NGF), brain-derived neurotrophic factor (BDNF), glial cell line-derived neurotrophic factor (GDNF) and ciliary neurotrophic factor (CNTF), have been observed in different brain areas $(73,74)$. Numerous experimental studies have indicated the reduction of NTFs in affected brain regions $(72,73)$. These changes in NTFs in AD are critical for neurodegenerative processes. Studies have observed that cognitive decline and the underlying pathologies of AD are associated with neurodegeneration in various regions of the brain, especially cholinergic neurons of the basal forebrain and their projections for the hippocampus and cortex $(72,75,76)$. It has been suggested that the loss of NTFs may be a mechanism involved in the pathogenesis of AD (77). The regulation of NTFs could be a suitable therapeutic target for AD treatment.

As a noninvasive neuromodulatory intervention, TMS or rTMS treatment may potentially regulate the expression of NTFs in the AD brain (Fig. 1), promoting neuronal differentiation and survival (78), and thus, exerting neurorestorative effects. Notably, a number of studies have indicated an increase in endogenous neurotrophic content (BDNF) in the affected brain regions after TMS therapy $(2,74)$. BDNF is a neurotrophin involved in synaptic plasticity changes and improves learning, memory and cognitive functions via the BDNF-tropomyosin receptor kinase B (TrkB) signaling pathway $(32,74)$. Therefore, BDNF serves a critical role in memory formation and synapsis. However, deficits in BDNF signaling are associated with AD (79). Furthermore, the expression levels of BDNF are altered in neurodegenerative 


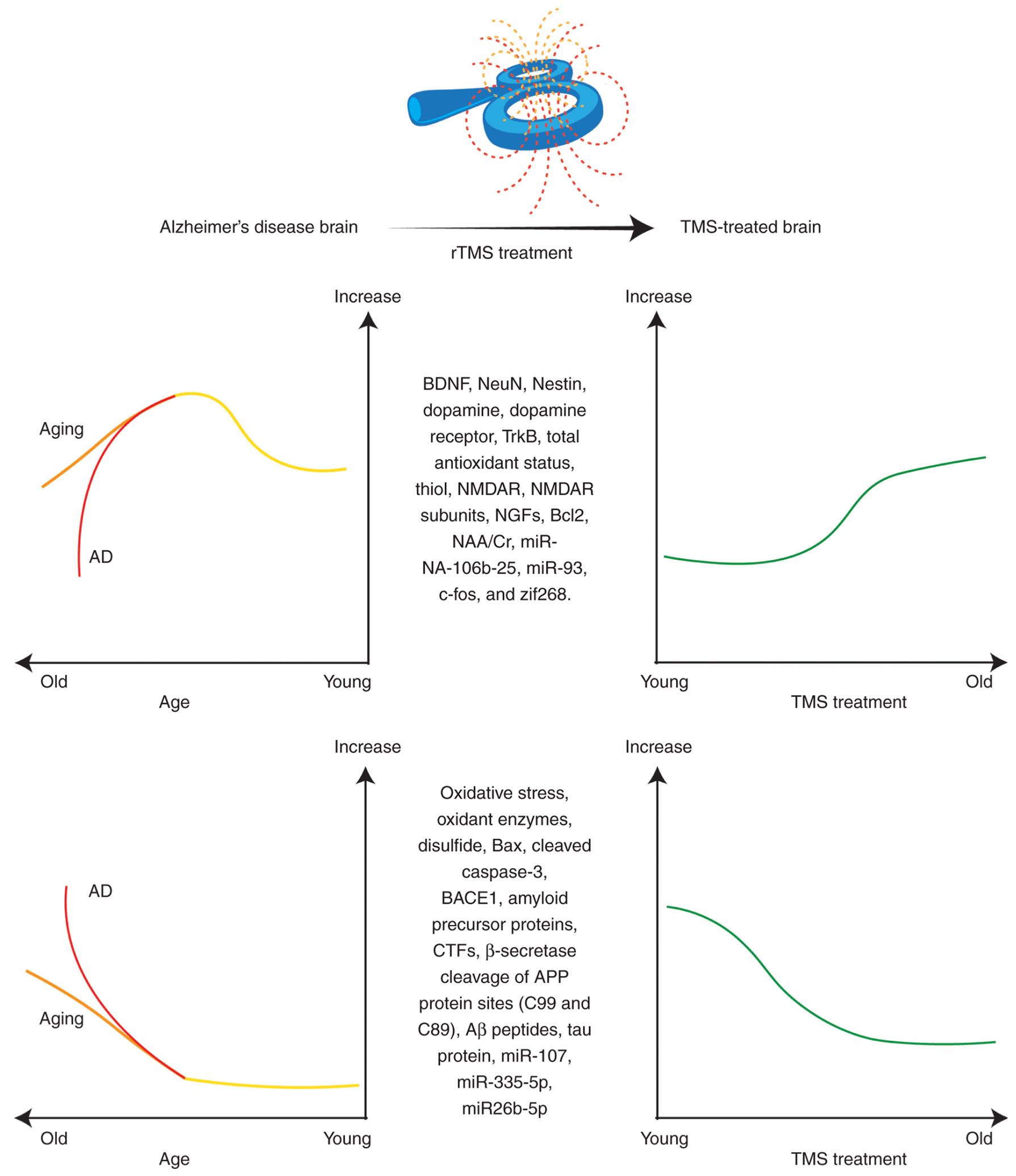

Figure 1. Schematic representation of the proposed paradigm demonstrating neurochemical changes in normal aging and AD, and the effects of TMS on these neurobiological changes, indicating that TMS may restore brain function. A $\beta$, amyloid- $\beta$; AD, Alzheimer's disease; APP, amyloid- $\beta$ precursor protein; BACE1, $\beta$-site APP-cleaving enzyme 1; BDNF, brain-derived neurotrophic factor; CTFs, C-terminal fragments; NAA/Cr, $N$-acetylaspartate/creatine; NeuN, neuronal nuclear protein; NGFs, nerve growth factors; NMDAR, N-methyl-D-aspartate receptor; rTMS, repetitive transcranial magnetic stimulation; TrkB, tropomyosin receptor kinase B; zif268, Zinc finger-containing transcription factor 268.

disorders, for example the BDNF levels are decreased in AD (80). A study by Choung et al (32) revealed an increase in BDNF expression, as well as neuronal nuclear protein
(NeuN) and neuroepithelial stem cell protein (Nestin), after $20 \mathrm{~Hz}$ HF-rTMS compared with the non-rTMS group or sham group in the hippocampus and cerebral cortex regions. It was 


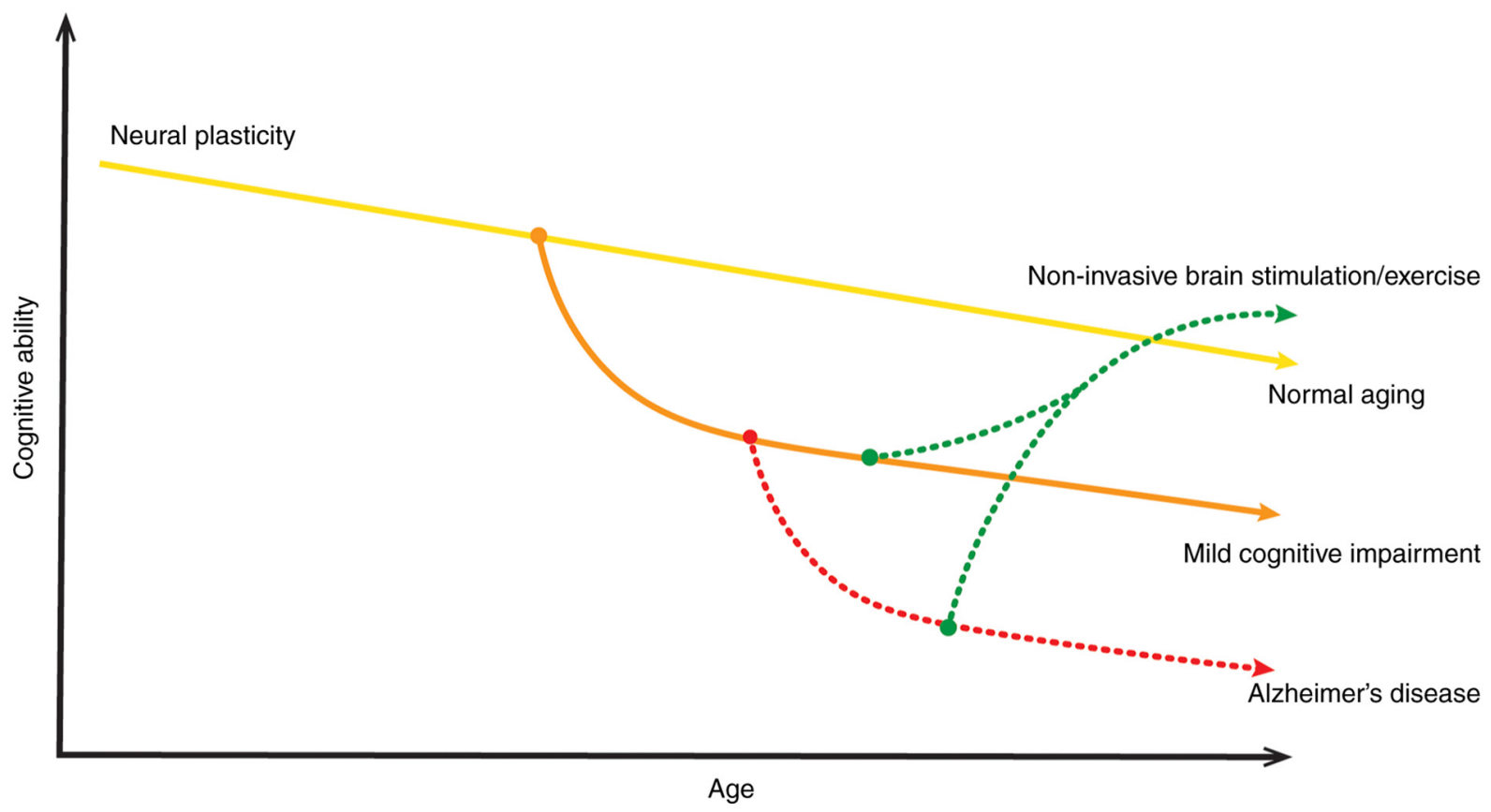

Figure 2. Proposed mechanism of cognitive decline and deterioration of neural plasticity throughout life, which may worsen by mild cognitive impairment and accentuate a maladaptive path to AD. Non-invasive brain stimulation or aerobic exercise improves cognitive ability and increases neural plasticity. Therefore, non-invasive brain stimulation or aerobic exercise exerts a neuroprotective effect on AD. AD, Alzheimer's disease.

concluded that rTMS exerted neurogenic and neuroprotective effects and promoted neurogenesis (Table I) (32). A similar increase in BDNF has also been observed after rTMS treatment in a number of other studies $(36,81)$. Additionally, rTMS treatment positively regulates the BDNF receptor TrkB. Chen et al (81) observed an increase in TrkB in the AD brain after $5 \mathrm{~Hz}$ HF-rTMS. In addition, LF-rTMS also regulates BDNF levels in AD (Table I) (82). A previous study revealed that $1 \mathrm{~Hz}$ LF-rTMS upregulates BDNF content in the hippocampal region of the AD brain (82). Tan et al (82) also reported the effects of LF-rTMS on another NTF, NGF, which is essential for growth, development, survival and neuronal population. The expression of NGFs has been found to be altered in AD (Table I). The $1 \mathrm{~Hz}$ LF-rTMS treatment upregulates NGF content in AD (A $\beta$ injected mice) group compared to control (saline injected) group (82). Similar results have also been published by Chen et al (83), who applied both 1 and $10 \mathrm{~Hz}$ rTMS and observed that both frequencies of rTMS regulated the brain levels of NTFs (BDNF and NGF), and these increased with increased frequency. Furthermore, glial cells, astrocytes and neurons secrete BDNF and NGF, which could be increased following rTMS treatment, therefore rescue memory deficit (82) In contrast to that in $\mathrm{AD}$, various studies have indicated that rTMS application tends to decrease BDNF levels in healthy volunteers $(84,85)$. However, the precise mechanisms of direct evaluation of BDNF levels in humans after TMS treatment remain unclear (86). BDNF levels are associated with TMS treatment, both during and after treatment. Briefly, these findings suggest that BDNF could be an ideal biomarker for TMS treatment for patients with AD.

Antioxidant effects of TMS application. Oxidative stress serves a key role in the etiology and pathogenesis of AD. The imbalance in cell redox status, ROS production and impaired antioxidant defense lead to oxidative stress (87). These forms of damage serve a pivotal role in cellular dysfunction, potentially harming the neurons in aging and neurodegenerative disorders, including AD. AD research has revealed that oxidative stress and free radical damage are associated with histopathological hallmarks of $\mathrm{AD}$, such as amyloid plaques and neurofibrillary tangles $(88,89)$. ROS are free radical oxygen byproducts containing an unpaired electron in their valence shell, and these are generated as a result of cellular respiration. The excessive buildup of ROS, including oxygen radical superoxide and hydrogen peroxide, in the cells or neurons causes DNA or RNA oxidative damage, leading to cell death and tissue damage (87). Mitochondrial dysfunction generates excessive ROS as the byproduct of the electron transport chain, ameliorating the risk of AD $(90,91)$. Therefore, oxidative stress and mitochondrial dysfunction adversely affect the brain, leading to aging and neurodegenerative disorders, particularly AD. Furthermore, studies have indicated that oxidative stress and BDNF are associated with each other $(89,92)$. In addition, oxidative stress could be considered a promising biomarker of AD prognosis (93). In line with this, TMS treatment noninvasively modulates and balances BDNF and oxidative stress levels, thus exerting beneficial antioxidant effects in patients with AD (Fig. 1) (36). Some studies have reported that rTMS increases BDNF levels and decreases oxidative stress in treatment-resistant depression (94), stroke (95) and experimental autoimmune encephalomyelitis (96). However, there are a limited number of experimental studies in the literature demonstrating the effects of TMS on oxidative stress in AD. Only a recent study by Velioglu et al (36) has analyzed the beneficial effects of rTMS on BDNF and oxidative stress levels in patients with AD. For this purpose, $20 \mathrm{~Hz}$ rTMS was applied to the lateral parietal cortex in patients with AD. The 


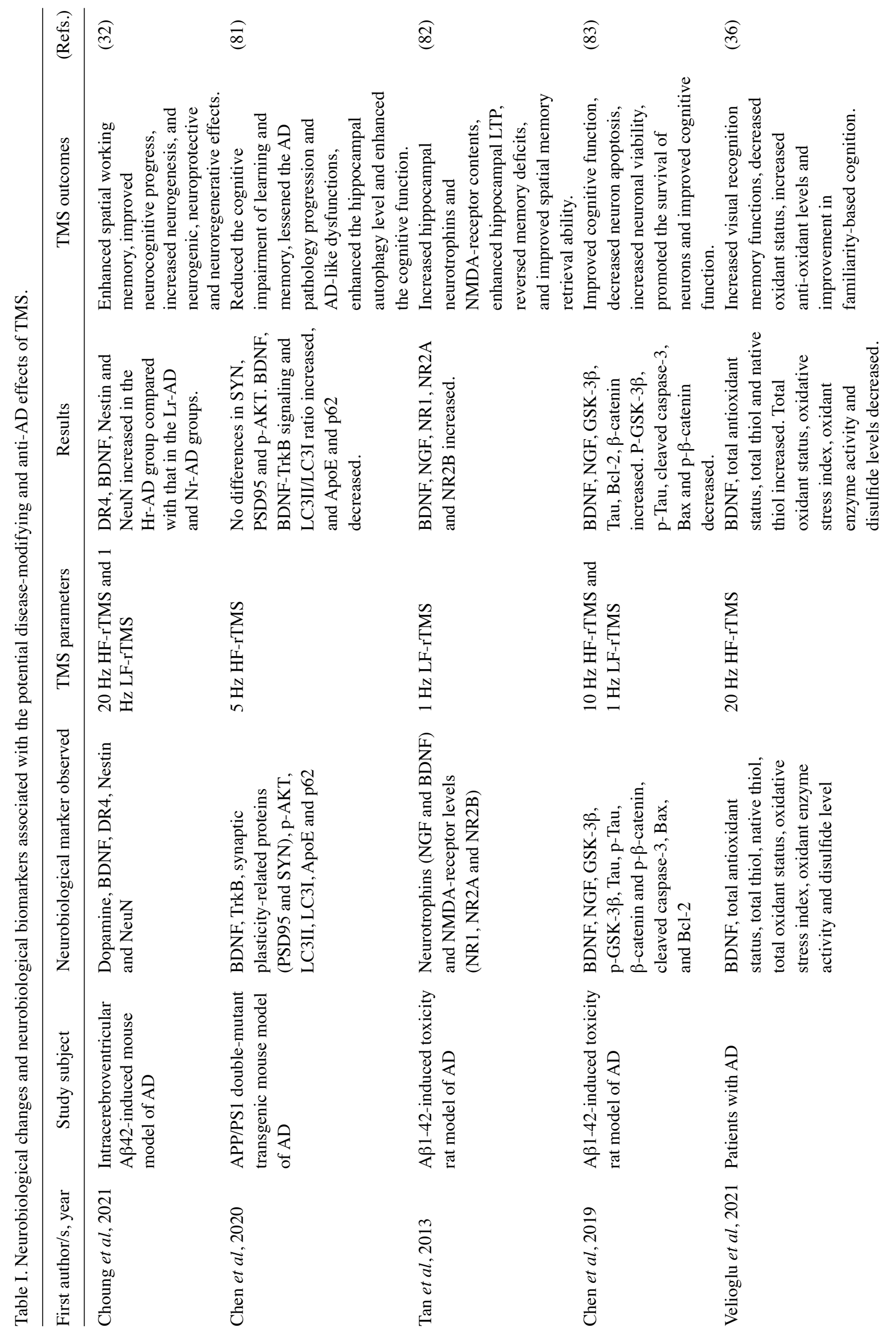




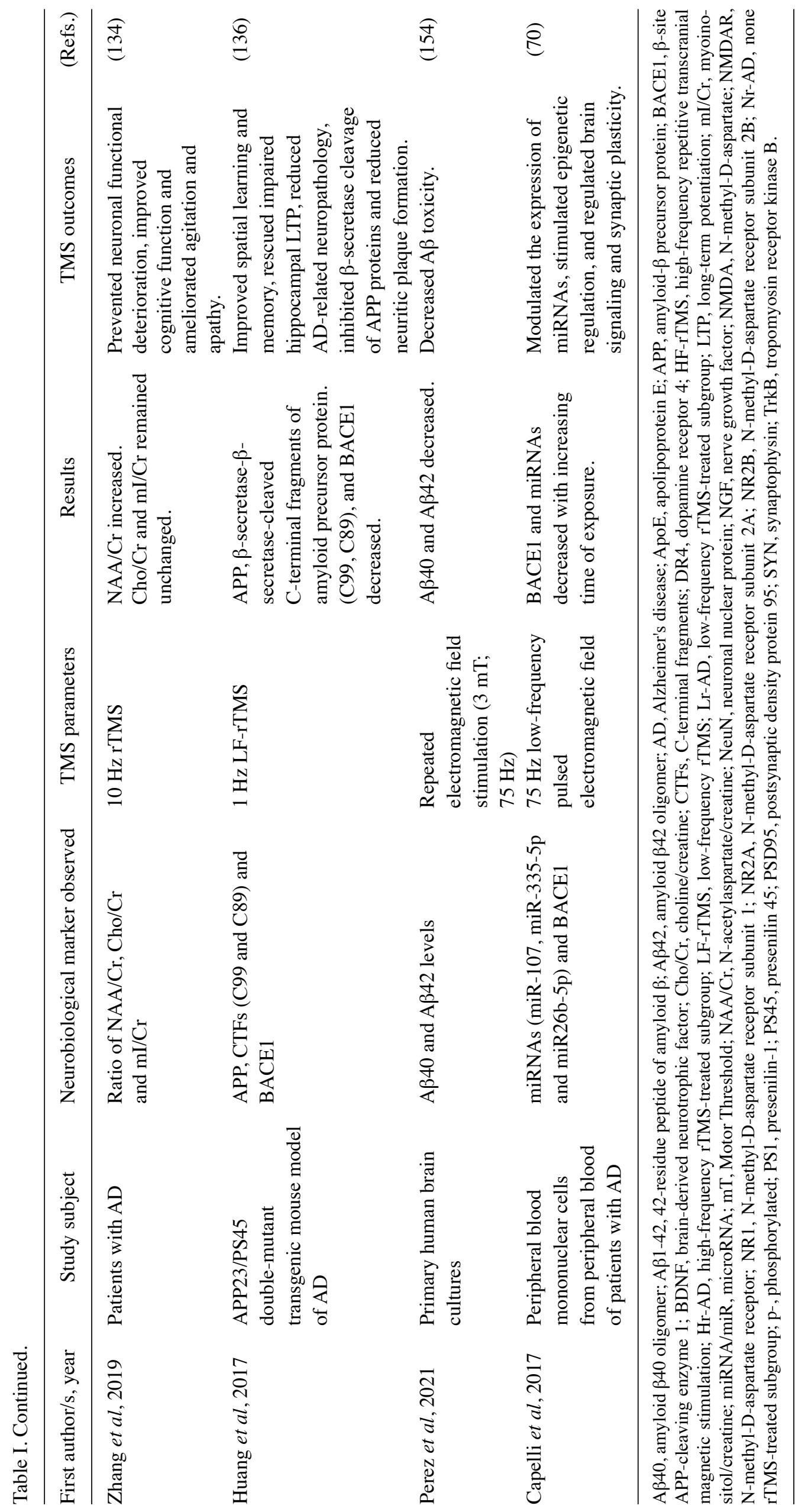


levels of BDNF, total antioxidant status, total thiol levels and native thiol levels were increased after $20 \mathrm{~Hz}$ rTMS treatment. Furthermore, the total oxidant status, oxidative stress index, oxidant enzyme activity and disulfide levels were decreased following left lateral parietal rTMS (Table I) (36). Oxidative stress could be an effective target for the treatment of neurodegenerative disorders; however, there remains a large research gap in terms of investigating the influence of TMS on oxidative stress, antioxidant defense systems, total oxidant/antioxidant status and antioxidant enzymes. More studies are required to fill this research gap.

TMS facilitates synapsis by regulating neurotransmitters. The onset of AD also negatively influences the metabolism, levels and functioning of synaptic neurotransmitters. There are important contributions of cholinergic and noncholinergic neurotransmitter systems behind the pathophysiological signaling in AD (97). Neurotransmitters are chemical messengers that are released from a nerve to stimulate other nerves across the synapse. Neurotransmitters, including dopamine, glutamate, aspartate and $\gamma$-aminobutyric acid (GABA), serve a key role in cognitive control, learning and memory development (98). Therefore, alterations in the metabolism and expression of neurotransmitters lead to synaptic dysfunction, cognitive impairment, learning disabilities and memory deficits. A number of studies have emphasized that the expression of neurotransmitters and receptors is markedly reduced in patients with AD $(97,99)$. Therefore, targeting neurotransmitters, as well as their receptors, could be a rational approach to overcome AD. NIBS by EMF from TMS has the potential to minimize symptoms and elucidate AD pathology by positively regulating neurotransmitter parameters (e.g. dopamine; Fig. 1).

Dopamine is a monoamine neurotransmitter produced in dopaminergic neurons; it is involved in synaptic plasticity and regulates mood, emotional stability, and cognitive and motor function (100). The dopamine receptors $\left(D_{1}, D_{2}, D_{3}\right.$, $\mathrm{D}_{4}$ and $\mathrm{D}_{5}$ ) are $\mathrm{G}$-protein-coupled receptors that are mostly expressed in the limbic system and cortex (101). The dopaminergic system serves a pivotal role in the pathophysiology of AD (102). The loss and decrease in dopamine content and its receptors are frequently reported in patients with $\mathrm{AD}$, causing motor impairment and cognitive decline $(99,103,104)$. TMS increases the levels of dopamine and dopamine receptors in patients with AD. However, a limited number of studies have been conducted regarding dopamine levels after TMS application. Furthermore, in healthy volunteers, dopamine tends to increase following deep TMS therapy (105). In a recent study by Choung et al (32), HF (20 Hz) and LF (1 Hz) rTMS were applied to assess dopamine levels and receptor concentrations after rTMS application. The findings suggested that HF-rTMS and LF-rTMS increased the dopamine levels in the hippocampus. The expression of dopamine receptor 4 (DR4) was increased after $1 \mathrm{~Hz}$ LF-rTMS in the hippocampus and cerebral cortex of the AD brain compared with that of the LF and non-rTMS AD groups (32). After TMS therapy, the dopamine levels are also increased in healthy volunteers $(105,106)$. The increases in dopamine levels after TMS could allow monitoring of the progress of the brain stimulation of patients with AD by TMS. The dopamine level also has the potential to be a biomarker for TMS treatment.
The N-methyl-D-aspartate receptor (NMDAR) is a critical molecule that serves a key role in synaptic transmission, synaptic plasticity, hippocampal long-term potentiation (LTP), learning and memory (107). NMDAR is a glutamate receptor that is important for excitatory neurotransmitter transmission, synapsis and memory formation (108). In $\mathrm{AD}, \mathrm{A} \beta$ plaques trigger excessive calcium $\left(\mathrm{Ca}^{2+}\right)$ influx, which enters into neurons via NMDARs, leading to gradual synaptic dysfunction and neuronal cell death (109). However, NMDAR is downregulated in patients with AD (110). Battaglia et al (111) observed neocortical plasticity impairment in patients with $\mathrm{AD}$ and amyloid precursor protein (APP)/presenilin-1 mice, which could cause functional deficits of NMDAR. It has been observed that TMS application can regulate neurotransmitters, including NMDAR expression, effectively affecting cognitive function (112). Low-frequency (1 Hz) rTMS increases NMDAR expression, also increasing NMDAR subunits (NR1, NR2A and NR2B) in the hippocampus, thus facilitating LTP and memory formation (82). Furthermore, an increase in NMDAR and vascular endothelial growth factor (VEGF) expression has been observed in a rat model of vascular dementia (VaD) following $5 \mathrm{~Hz}$ rTMS treatment (112) and $1 \mathrm{~Hz}$ rTMS (69). The increase in NMDAR-related amino acids has also been observed after LF-rTMS (1 Hz) by Niimi et al (113) in patients after stroke. Furthermore, it has been observed that upregulation of NMDAR contributes to enhanced neurotrophic effects (107). Therefore, treating memory deficits promotes synaptic plasticity, hippocampal plasticity and memory formation. Impaired NMDAR function could alter plasticity in AD. An improved understanding of AD pathophysiology would facilitate the development of a novel treatment that regulates NMDAR function and improves plasticity, learning and memory deficits in patients with AD. Furthermore, an increase in NMDAR expression facilitates neuronal recovery following rTMS.

TMS suppresses apoptosis and exerts neuroprotective effects. In neurodegenerative disorders, particularly AD, excessive neuronal loss is considered to be common due to apoptosis, which acts as a major cell death pathway in neurons $(114,115)$. In $\mathrm{AD}$, the levels of apoptosis-related Bcl-2 are downregulated, while those of Bax and cleaved caspase-3 are upregulated (116). TMS noninvasively regulates and balances the apoptotic pathways, thus exerting its beneficial effects on the brains of patients with AD (Fig. 1) $(33,82,83)$. TMS suppresses the apoptotic pathways by inhibiting several members of the Bcl-2 family, particularly $\mathrm{Bad}, \mathrm{Bax}$ and $\mathrm{Bcl}-\mathrm{X}_{\mathrm{L}}$, which enhances apoptosis. rTMS (1 and $10 \mathrm{~Hz}$ ) treatment in AD mouse models increased apoptosis, as reflected by enhanced Bcl-2 expression and decreased levels of Bax and cleaved caspase-3 (83). Similarly, in a VaD rat model, $1 \mathrm{~Hz}$ rTMS was found to increase Bcl-2 expression and suppress Bax expression (69). A study on a middle cerebral artery occlusion rat model revealed that $10 \mathrm{~Hz}$ rTMS treatment markedly upregulated Bcl-2 expression and decreased the levels of Bax and TUNEL-positive cells in the ischemic hippocampus (117). Studies have demonstrated that rTMS suppresses the apoptosis and apoptotic pathways, and thus, rTMS may improve cognitive impairment and exert neuroprotective effects on neurons in an affected brain, particularly in $\mathrm{AD}(78,83,118)$. rTMS regulates $\mathrm{Bcl}-2$ and Bax expression, 
which can promote the functional recovery of cognitive impairments and enhance the protective mechanisms of learning and memory with increased synaptic plasticity; this mechanism may be mediated by the BDNF signaling pathway (117). More research is required to study the effects of TMS on apoptosis in AD pathology. However, TMS could be a promising candidate for the clinical treatment of AD.

Cognitive rehabilitation and improvement in memory and executive functions by TMS. AD is associated with progressive and irreversible loss of memory, decline in cognitive function, and deterioration of attention, executive function, thinking and behavioral abilities. In AD, language, reasoning, social behavior, verbal and auditory naming, and the ability to carry out simple tasks are also severely impaired due to underlying neurodegenerative processes (119-121). Executive functions, including working memory and selective attention, are typically associated with the dorsolateral prefrontal cortex (DLPFC). Impaired DLPFC neuroplasticity is associated with the physiopathology of $\mathrm{AD}$, severely affecting the executive functions in patients with AD $(122,123)$. Some studies have assessed DLPFC plasticity in patients with AD using paired associative stimulation (PAS), a TMS paradigm, as a measure of DLPFC and potentiation of cortical-evoked activity (124). PAS is the combination of repeated pairing of single pulses of peripheral nerve electrical stimulation with single pulses of TMS of the contralateral cerebral cortex. PAS (TMS with electroencephalography) results in short-term modulation of corticospinal excitability and induces LTP-like plasticity in the different pathological stages of AD $(122,124,125)$. Furthermore, the impaired LTP-like cortical plasticity could be a potential biomarker for the prognosis of AD (126). A recent study revealed that $20 \mathrm{~Hz}$ rTMS improved cognition in AD (29). Cortical LTP-like plasticity is associated with cognitive function improvement in patients with AD following rTMS (49). In view of this, TMS positively regulates executive function, cognitive ability and visuospatial learning behavior in DLPFC (127).

Numerous studies have highlighted the fact that TMS can improve cognitive and executive functions, memory and language ability in patients with $\operatorname{AD}(29,33,66,128)$. However, to the best of our knowledge, the molecular and metabolic changes following rTMS are still unknown. The effects of LF-rTMS and HF-rTMS on neuronal plasticity and the learning process in memory tasks have been studied extensively. Cappa et al (129) reported that $20 \mathrm{~Hz}$ rTMS activates the DLPFC, facilitating object and action naming. Similarly, high-frequency $(20 \mathrm{~Hz})$ rTMS applied to the left and right DLPFC improves naming performance not only in mild AD (130), but also in severe AD (131). rTMS may enable the intrinsic ability of the brain to recover damaged function (131). Another study by Cotelli et al (132) suggested that rhythmic HF-rTMS over DLPFC exerts beneficial effects on sentence comprehension and may be used to treat language dysfunction in patients with AD. However, the exact underlying mechanisms involved in rTMS improving naming and speech are still elusive. Ahmed et al (133) demonstrated that (20 Hz) HF-rTMS for five daily sessions over the left and right DLPFC improved cognitive functions in patients with mild to moderate AD. Zhang et al (134) combined HF-rTMS with cognitive training (rTMS-CT), revealing that the ratio of $\mathrm{N}$-acetylaspartate/creatine (NAA/Cr) increased in the left
DLPFC of AD patients. Furthermore, the choline (Cho)/Cr and myoinositol $(\mathrm{mI}) / \mathrm{Cr}$ ratios remained unchanged in the rTMS-CT group compared to sham group (sham rTMS with CT). The study also proposed that rTMS-CT may improve cognitive function in patients with $\mathrm{AD}$ who are in a mild to moderate stage (134). On the other hand, low-frequency $(1 \mathrm{~Hz})$ rTMS applied over the left DLPFC of patients with AD has been found to facilitate no change in memory performance. However, when applied to the right DLPFC, low-frequency $(1 \mathrm{~Hz})$ rTMS improves recognition memory function (135). Additionally, $20 \mathrm{~Hz}$ rTMS on the lateral parietal cortex in patients with AD increases visual recognition memory (36). Furthermore, $1 \mathrm{~Hz}$ LF-rTMS could potentially rescue spatial learning and memory deficits accompanied by impaired LTP-plasticity in the hippocampal CA1 region in an APP23/PS45 double transgenic mouse model of AD (136). Future studies will also investigate the short- and long-term effects of rTMS on AD and cognitive functions (48). Furthermore, rTMS improves spatial working memory in mouse models of AD (32), visuospatial reasoning, and trained associative memory in patients with AD (137). Accordingly, these studies have concluded that rTMS could be beneficially and therapeutically effective for NIBS, behavioral recovery and cognitive rehabilitation, as well as a well-tolerated therapy for patients with AD. The cortical changes induced by rTMS can improve synapsis and neuronal plasticity (138). In addition, there are only limited experimental studies highlighting the neurobiological changes during cognitive rehabilitation by rTMS (134). We hypothesize that changes in metabolites or other molecular indices could serve as biomarkers following rTMS, allowing for further improvement of the accurate and precise functioning of neurons in $\mathrm{AD}$. Therefore, future studies should focus on the levels of metabolites and $\mathrm{NAA} / \mathrm{Cr}, \mathrm{Cho} / \mathrm{Cr}$ and $\mathrm{mI} / \mathrm{Cr}$ ratios after TMS treatment to further explore the therapeutic effects of rTMS on cognitive rehabilitation in AD.

TMS modulates gene expression and miRNA expression profiles in $A D$. miRNAs are novel, short ( 22 nucleotides), evolutionarily conserved, noncoding RNA molecules that are post-transcriptional regulators of gene expression, cell proliferation, differentiation and apoptosis $(139,140)$. miRNAs serve an important role in regulating the translation and stability of mRNAs, are involved in pathological processes, and inhibit their translation by guiding RNA-induced silencing complex and complement binding or interacting with the 3'-untranslated region of mRNA $(141,142)$. An increasing number of studies have demonstrated that approximately one-half of the miRNAs are in proximity to other miRNAs and regulate the activity of $60 \%$ of all protein-coding genes $(140,143)$. A single miRNA regulates almost 400 different mRNAs (144). It has also been reported that miRNAs serve a pivotal role in synaptic formation, development function, plasticity and neuronal processes, such as neural proliferation, differentiation, maturation and migration (145-147). Studies have demonstrated that miRNAs contribute to the development of numerous diseases and neurodegenerative disorders, including AD $(141,147)$. The changes in the levels of miRNAs could also serve as diagnostic biomarkers for AD $(148,149)$. Different miRNAs have been found to be associated with the accumulation of $A \beta$ peptides and tau phosphorylation $(141,150)$, leading 
to the pathophysiology of AD. Furthermore, miRNAs also regulate oxidative stress and vice versa (142).

TMS might also have the ability to regulate miRNA expression in AD (Fig. 1). In line with this, future studies are required to clarify whether TMS regulates gene expression and miRNAs. However, a few studies have reported the effects of TMS on miRNAs. Liu et al (151) investigated the effects of rTMS on the proliferation of neural stem cells (NSCs) and their association with miRNAs expression in vivo. The $10 \mathrm{~Hz}$ rTMS treatment was associated with the upregulation of the miRNA-106b-25 cluster and miR-93, the downregulation of $\mathrm{p} 21$ protein and enhanced NSC proliferation (151).Liu et al (152) also investigated the effects of rTMS on the proliferation of neural progenitor cells (NPCs) and the association with miR-106b expression when $10 \mathrm{~Hz}$ rTMS was applied to the NPCs cultured from a rat hippocampus. The results revealed that rTMS enhanced NPC proliferation by upregulating miR-106b expression by inhibiting p21 expression (152). Another study by Aydin-Abidin et al (153) examined the effects of low-frequency $(1 \mathrm{~Hz})$ rTMS, high-frequency $(10 \mathrm{~Hz})$ rTMS and intermittent theta-burst stimulation (iTBS) on the expression of immediate early gene (IEG) proteins c-Fos and zinc finger protein 268 (zif268) in the rat brain. It was observed that LF-rTMS and HF-rTMS increased c-Fos protein expression in the cortical areas. LF-rTMS did not regulate zif268 expression, but HF-rTMS increased zif268 expression in the primary motor and sensory cortices. Additionally, iTBS increased c-Fos expression in limbic cortices only and zif268 levels in all cortical areas (153). One study investigated the effects of a low-frequency pulsed EMF (LF-PEMF) on protein (BACE1) and miRNA expression involved in AD (70). It was revealed that $75 \mathrm{~Hz}$ LF-PEMF modulated the expression of miR-107, miR-335-5p and miR26b-5p in an experimental cell model of peripheral blood mononuclear cells from patients with AD. miR-107 regulates $\beta$-site APP-cleaving enzyme 1 (BACE1), which serves a role in the amyloidogenic pathway of the APP pathway. An increasing LF-PEMF exposure time reduced miRNAs expression and BACE1 level (Table I) (70). Recently, Perez et al (154) reported that repeated EMF stimulation reduces $A \beta 40$ and $A \beta 42$ peptides in primary human brain cultures. In a similar vein, another study reported that low-frequency $(1 \mathrm{~Hz})$ rTMS progressively downregulated APP and its $\mathrm{C}$-terminal fragments (CTFs) in the $\mathrm{AD}$ mouse brain. The decrease in $\beta$-secretase generated C99 and C89 fragments, and BACE1 could be observed following $1 \mathrm{~Hz}$ rTMS application in transgenic mice (136). Accordingly, it was also demonstrated that rTMS may suppress $\beta$-secretase cleavage of APP proteins, contributing toward the decrease in $A \beta$ neuropathology, such as neuritic plaque formations, APP processing and BACE1 expression, which may contribute to the amelioration of cognitive functioning and synaptic plasticity (136). Therefore, TMS exerts anti-AD effects by targeting $\mathrm{A} \beta$ peptides, modulating gene expression in the $\mathrm{AD}$ brain and reducing $\mathrm{AD}$-related neuropathology in patients with AD.

\section{Potential side effects associated with TMS treatment}

Although TMS exerts extensive therapeutic effects, various possible side effects have also been disclosed previously. Headache (or neck and scalp pain) is considered the common side effect, which might result in accidental seizures, hypomania or unwanted psychiatric complications (155). Transient headache is reported by $20-40 \%$ of the patients undergoing TMS (both low- and high-frequency), but seizures $(>1 \%)$, hypomania and cognitive changes are very rare or negligible (156). TMS is also unlikely to cause structural changes, histotoxicity or tissue damage, although unintended long-term changes in the brain are theoretically possible (157). Additionally, the clicking sound of TMS and skin stimulation cause multi-sensory experiences and trigger shifts of spatial attention $(158,159)$. The incorrect positioning of the coil may cause a placebo (160) or unwanted effect, affecting the behavioral, physiological and cognitive processes. However, the safety guidelines for TMS suggested by Wassermann (161) and Chen et al (162) recommend frequencies, current intensities and trains of stimuli to prevent side effects of the treatment. In addition, TMS parameters combined with short trains and long inter-train intervals carry a lower risk of side effects (163).

\section{Discussion}

Aging is the major risk factor behind the pathogenesis of cognitive decline, dementia and neurodegenerative disorders, including AD (14). Being a severe form of dementia, AD is a multifactorial, chronic and progressive disorder leading toward memory decline and cognitive dysfunctions (164). The clinicopathological features of AD brains include proteinopathy (amyloid plaques neurofibrillary tangles) $(164,165)$. Despite tremendous advancements in the field of neurology and medical sciences, little is known regarding the mechanism behind this complex neurodegenerative disease. AD treatment is still a major challenge for researchers and physicians. Furthermore, there are no effective drugs or nondrug treatment options that can cure AD or stop or slow its progression. Neurons may be damaged or have already died due to neurodegenerative disorders, but TMS has the potential to treat and restore them due to its neuroprotective, neuro-regenerative and disease-modifying effects $(32,36)$. Accordingly, TMS could offer a safe and noninvasive technique for the treatment of AD. However, the association between the molecular mechanisms responsible for the treatment of AD after TMS is still elusive. TMS therefore remains a topic of research, and much progress has been made to find its mechanism. Studies are continuously being conducted to elucidate the mechanisms and effects of TMS on the AD-affected brain. At present, a number of clinical trials are ongoing to further investigate the molecular mechanisms behind the disease-modifying effects of TMS on AD and other neurodegenerative disorders (www. clinicaltrials.gov; Table II).

The present review highlights the effects of TMS on neurobiological and neurochemical changes in AD. At the molecular level, TMS facilitates neural restoration, synaptic plasticity, neurotransmission, neural regeneration, neural development, neuroprotection and cognitive rehabilitation, and regulates gene expression in AD. TMS positively regulates inflammatory and apoptotic mechanisms, mitochondrial enzymatic activities, modulation of gene expression (miRNA expression profiles), cell redox status and the amyloidogenic processes (Fig. 1). Following TMS, the expression of the following neurochemicals increases: BDNF, NeuN, Nestin, dopamine, DR4 (32), TrkB (81), total antioxidant status, total 


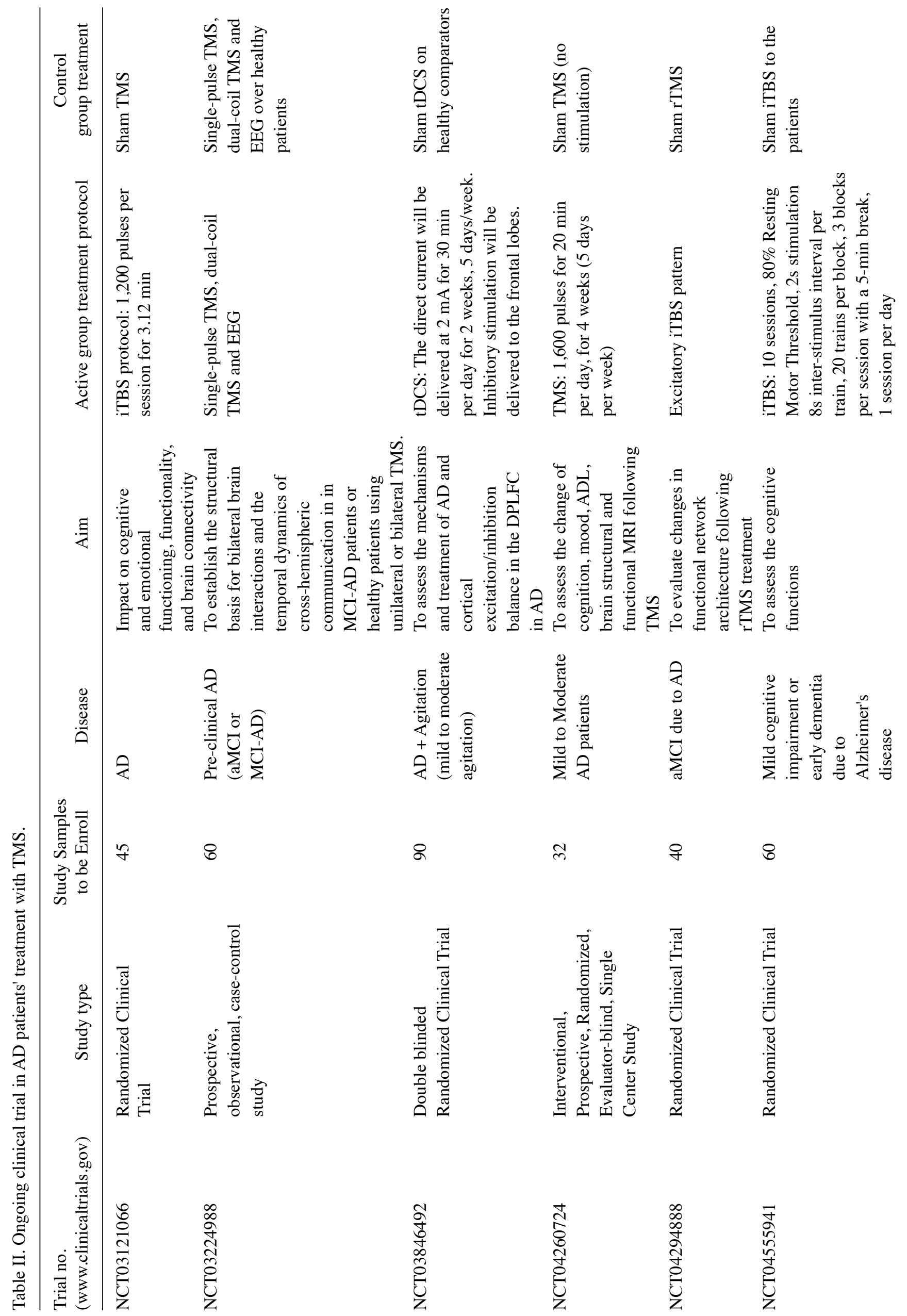


BASHIR et al: BRAIN STIMULATION AND AD

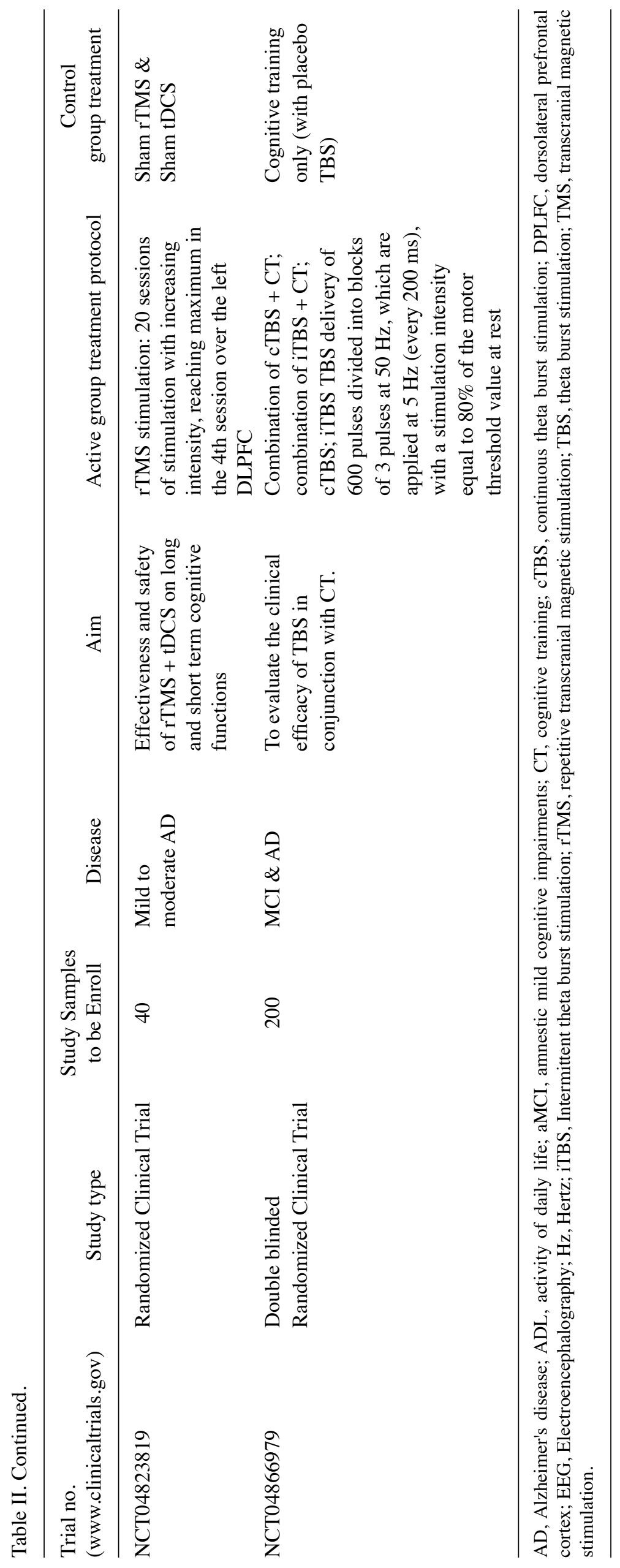


thiol, native thiol (36), NMDAR, NMDAR subunits (NR1, NR2A, and NR2B), NGF (82), Bcl-2, Tau (83), NAA/Cr (134), miRNA-106b-25, miR-93 $(151,152)$ and IEG proteins (c-Fos and zif268) (153). Furthermore, TMS tends to decrease the levels of total oxidant status, oxidative stress index, oxidant enzyme activity, disulfide (36), Bax, cleaved caspase-3, p-Tau (83), miR-107, miR-335-5p, miR26b-5p (70), BACE1, APP, CTFs, $\beta$-secretase-generated C99 and C89, $\beta$-secretase cleavage of APP proteins, and A $\beta$ peptides (136). In addition, the disease-modifying effects of TMS treatment depend on the frequency and site of stimulation (166-168). Neurobiological changes have been observed differentially with different stimulations (low or high frequency) (153) and stimulation sites (i.e., DLPFC, left parietal cortex, hippocampus and cortex) $(32,36,133,136)$. Furthermore, TMS tends to improve cognitive functioning (134), cortical plasticity (49), naming performance (129), language function (132), recognition memory function (135), visual recognition memory (36), spatial working memory (32), visuospatial reasoning and trained associative memory (137) in patients with AD. Therefore, the anti-AD effects of TMS facilitate an increase in cortical excitability, induce potentiation, stimulate synaptic plasticity, recover impaired molecular functions, enhance cognitive functions and re-establish neural connections in patients with AD.

In addition, there are a limited number of research-based studies in the literature demonstrating TMS-induced neurochemical and neurobiological changes in AD. We suggest that future studies on the therapeutic effects of TMS on oxidative stress, $\mathrm{Ca}^{+}$ions, non-neural/glial cells (oligodendrocytes, astrocytes, microglia and further NSCs), NTFs (NGF, BDNF, GDNF, CNTF and VEGF), nerve growth factors, neurotransmitters (dopamine, glutamate, aspartate, GABA and NMDA), apoptosis-related proteins (Bcl-2, Bax, caspases and TUNEL-positive cells), genetic expression, miRNA expression, protein expression, enzymatic activity and metabolites, are required to further explore the beneficial anti-AD mechanism of TMS in patients with AD. Knowledge of these changes may clarify the structural and functional changes in the brain, as well as neuroprotection, neurodevelopmental and neurorestorative correlation with rTMS in AD.

\section{Conclusion}

The main goal of the present review was to understand the changes in the neurobiological parameters in the brain following TMS in neurodegenerative disorders, particularly AD. Although the number of studies investigating TMS-induced neurochemical and neurobiological changes in AD is still low, the anti-AD and disease-modifying effects of TMS can open a pathway for researchers to further explore its molecular mechanism. As the neurobiological and clinicopathological alterations and modifications in AD are not well studied following TMS, more experimental studies comprising inflammatory, apoptotic, neurodegenerative, genetic and neuroprotective changes, as well as functional brain imaging, are required to determine the site- and stimulation-dependent TMS-induced disease-modifying changes in the brain. TMS-based NIBS has promising effects on functional recovery through neural restoration, neuroprotection and neural differentiation.

\section{Acknowledgements}

Not applicable.

\section{Funding}

No funding was received.

\section{Availability of data and materials}

Data sharing is not applicable to this article, as no data sets were generated or analyzed during the current study.

\section{Authors' contributions}

$\mathrm{SB}, \mathrm{MU}, \mathrm{TA}$ and MA were responsible for the conception of the present study. SB, MU and MA searched the literature. SB, MU, TA, RAK, AN, ZT, WKY, IT, ADT and SM contributed to writing the manuscript and figure design. TA, RAK, AN, ZT, WKY, IT, ADT and SM critically revised and corrected the manuscript. Data authentication is not applicable. All authors have read and approved the final manuscript.

\section{Ethics approval and consent to participate}

Not applicable.

\section{Patient consent for publication}

Not applicable.

\section{Competing interests}

The authors declare that they have no competing interests.

\section{References}

1. Guarino A, Favieri F, Boncompagni I, Agostini F, Cantone M and Casagrande M: Executive functions in Alzheimer disease: A systematic review. Front Aging Neurosci 10: 437, 2019.

2. Weiler M, Stieger KC, Long JM and Rapp PR: Transcranial magnetic stimulation in Alzheimer's disease: Are we ready? eNeuro 7, 2020.

3. Weller J and Budson A: Current understanding of Alzheimer's disease diagnosis and treatment. F1000Res 7: F1000 Faculty Rev-1161, 2018.

4. 2020 Alzheimer's disease facts and figures. Alzheimers Dement 16: 391-460, 2020.

5. Uddin M, Kabir M, Jakaria M, Sobarzo-Sánchez E, Barreto GE, Perveen A, Hafeez A, Bin-Jumah MN, Abdel-Daim MM and Ashraf GM: Exploring the potential of neuroproteomics in Alzheimer's disease. Curr Top Med Chem 20: 2263-2278, 2020.

6. Koper MJ, Van Schoor E, Ospitalieri S, Vandenberghe R, Vandenbulcke M, von Arnim CAF, Tousseyn T, Balusu S, De Strooper B and Thal DR: Necrosome complex detected in granulovacuolar degeneration is associated with neuronal loss in Alzheimer's disease. Acta Neuropathol 139: 463-484, 2020.

7. Hur JY, Frost GR, Wu X, Crump C, Pan SJ, Wong E, Barros M, Li T, Nie P,Zhai Y, et al: The innate immunity protein IFITM3 modulates $\gamma$-secretase in Alzheimer's disease. Nat Aust 586: 735-740, 2020.

8. Butterfield DA and Mattson MP: Apolipoprotein E and oxidative stress in brain with relevance to Alzheimer's disease. Neurobiol Dis 138: 104795, 2020.

9. Bhatt S, Puli L and Patil CR: Role of reactive oxygen species in the progression of Alzheimer's disease. Drug Discov Today 26: 794-803, 2021. 
10. Olajide OJ, Gbadamosi IT, Yawson EO, Arogundade T, Lewu FS, Ogunrinola KY, Adigun OO, Bamisi O, Lambe E, Arietarhire LO, et al: Hippocampal degeneration and behavioral impairment during Alzheimer-like pathogenesis involves glutamate excitotoxicity. J Mol Neurosci 71: 1205-1220, 2021.

11. Zhao Y, Zhan JK and Liu Y: A perspective on roles played by immunosenescence in the pathobiology of Alzheimer's disease. Aging Dis 11: 1594-1607, 2020.

12. Uddin MS, Al Mamun A, Rahman M, Behl T, Perveen A, Hafeez A, Bin-Jumah MN, Abdel-Daim MM and Ashraf GM: Emerging proof of protein misfolding and interactions in multifactorial Alzheimer's disease. Curr Top Med Chem 20: 2380-2390, 2020.

13. Butterfield DA and Boyd-Kimball DA: Mitochondrial oxidative and nitrosative stress and Alzheimer disease. Antioxidants (Basel) 9: 818, 2020.

14. Sengoku R: Aging and Alzheimer's disease pathology. Neuropathol Appl Neurobiol 40: 22-29, 2020.

15. Wegiel J,Flory M,Kuchna I,Nowicki K,MaSY,Wegiel J,Badmaev E, Leon M, Wisniewski T and Reisberg B: Clinicopathological staging of dynamics of neurodegeneration and neuronal loss in Alzheimer disease. J Neuropathol Exp Neurol 80: 21-44, 2021.

16. Pei YA, Davies J, Zhang M and Zhang HT: The role of synaptic dysfunction in Alzheimer's disease. J Alzheimer's Dis 76: 49-62, 2020.

17. Teipel SJ, Fritz HC and Grothe MJ; Alzheimer's Disease Neuroimaging Initiative: Neuropathologic features associated with basal forebrain atrophy in Alzheimer disease. Neurology 95 e1301-e1311, 2020

18. Amini M, Pedram MM, Moradi A, Jamshidi M and Ouchani M: Single and combined neuroimaging techniques for Alzheimer's disease detection. Comput Intell Neurosci 2021: 9523039, 2021.

19. Zetterberg $\mathrm{H}$ and Burnham SC: Blood-based molecular biomarkers for Alzheimer's disease. Mol Brain 12: 26, 2019.

20. Jack CR Jr, Bennett DA, Blennow K, Carrillo MC, Dunn B, Haeberlein SB, Holtzman DM, Jagust W, Jessen F, Karlawish J, et al: NIA-AA research framework: Toward a biological definition of Alzheimer's disease. Alzheimer's Dement 14: 535-562, 2018.

21. Lee JC, Kim SJ, Hong S and Kim Y: Diagnosis of Alzheimer's disease utilizing amyloid and tau as fluid biomarkers. Exp Mol Med 51: 1-10, 2019

22. Park JE, Lim DS, Cho YH, Choi KY, Lee JJ, Kim BC, Lee KH and Lee JS: Plasma contact factors as novel biomarkers for diagnosing Alzheimer's disease. Biomark Res 9: 5, 2021.

23. Zetterberg H: Blood-based biomarkers for Alzheimer's disease-An update. J Neurosci Methods 319: 2-6, 2019.

24. Young PNE, Estarellas M, Coomans E, Srikrishna M, Beaumont H, Maass A, Venkataraman AV, Lissaman R, Jiménez D, Betts MJ, et al: Imaging biomarkers in neurodegeneration: Current and future practices. Alzheimers Res Ther 12: 49, 2020.

25. O'Dell RS, Mecca AP, Chen MK, Naganawa M, Toyonaga T, Lu Y, Godek TA, Harris JE, Bartlett HH, Banks ER, et al: Association of $\mathrm{A} \beta$ deposition and regional synaptic density in early Alzheimer's disease: A PET imaging study with $\left[{ }^{11} \mathrm{C}\right]$ UCB-J. Alzheimer's Res Ther 13: 11, 2021

26. Sujathakumari B, Shetty MC, Lakshitha H, Mehulkumar PJ and Suma S: Predictive analysis for early detection of Alzheimer's disease. In: Data Intelligence and Cognitive Informatics. Springer, pp 709-723, 2021.

27. Song A, Johnson N, Ayala A, Thompson AC and Brain: Optical coherence tomography in patients with Alzheimer's disease: What can it tell us? Eye 13: 1-20, 2021.

28. Segal Y, Segal L, Blumenfeld-Katzir T, Sasson E, Poliansky V, Loeb E, Levy A, Alter A and Bregman N: The effect of electromagnetic field treatment on recovery from ischemic stroke in a rat stroke model: Clinical, imaging, and pathological findings. Stroke Res Treat 2016: 6941946, 2016.

29. Lefaucheur JP, Aleman A, Baeken C, Benninger DH, Brunelin J, Di Lazzaro V, Filipović SR, Grefkes C, Hasan A, Hummel FC, et al: Evidence-based guidelines on the therapeutic use of repetitive transcranial magnetic stimulation (rTMS): An update (2014-2018). Clinical neurophysiology 131: 474-528, 2020.

30. Ba M, Ma G, Ren C, Sun X and Kong M: Repetitive transcranial magnetic stimulation for treatment of lactacystin-induced Parkinsonian rat model. Oncotarget 8: 50921-50929, 2017

31. Tasset I, Medina FJ, Jimena I, Agüera E, Gascón F, Feijóo M, Sánchez-López F, Luque E, Peña J, Drucker-Colín R and Túnez I: Neuroprotective effects of extremely low-frequency electromagnetic fields on a Huntington's disease rat model: Effects on neurotrophic factors and neuronal density. Neuroscience 209: $54-63,2012$
32. Choung JS, Kim JM, Ko MH, Cho DS and Kim M: Therapeutic efficacy of repetitive transcranial magnetic stimulation in an animal model of Alzheimer's disease. Sci Rep 11: 437, 2021.

33. Chou YH, Ton That V and Sundman M: A systematic review and meta-analysis of rTMS effects on cognitive enhancement in mild cognitive impairment and Alzheimer's disease. Neurobiol Aging 86: 1-10, 2020.

34. Weise K, Numssen O, Thielscher A, Hartwigsen G and Knösche TR: A novel approach to localize cortical TMS effects. NeuroImage 209: 116486, 2020.

35. Zorzo C, Higarza SG, Méndez M, Martínez JA, Pernía AM and Arias JL: High frequency repetitive transcranial magnetic stimulation improves neuronal activity without affecting astrocytes and microglia density. Brain Res Bull 150: 13-20, 2019.

36. Velioglu HA, Hanoglu L, Bayraktaroglu Z, Toprak G, Guler EM, Bektay MY, Mutlu-Burnaz O and Yulug B: Left lateral parietal rTMS improves cognition and modulates resting brain connectivity in patients with Alzheimer's disease: Possible role of BDNF and oxidative stress. Neurobiol Learn Mem 180: 107410 2021.

37. Luo J, Zheng H, Zhang L, Zhang Q, Li L, Pei Z and Hu X: High-frequency repetitive transcranial magnetic stimulation (rTMS) improves functional recovery by enhancing neurogenesis and activating BDNF/TrkB signaling in ischemic rats. Int J Mol Sci 18: 455, 2017.

38. Heath A, Taylor J and McNerney MW: rTMS for the treatment of Alzheimer's disease: Where should we be stimulating? Expert Rev Neurother 18: 903-905, 2018.

39. Bashir S, Mizrahi I, Weaver K, Fregni F and Pascual-Leone A: Assessment and modulation of neural plasticity in rehabilitation with transcranial magnetic stimulation. PM R 2 (12 Suppl 2): S253-S268, 2010.

40. Mann SK and Malhi NK: Repetitive transcranial magnetic stimulation. In: StatPearls StatPearls Publishing Copyright ${ }^{\circledR}$ 2021, StatPearls Publishing LLC., Treasure Island (FL), 2021.

41. Miniussi C and Ruzzoli M: Transcranial stimulation and cognition. Handb Clin Neurol 116: 739-750, 2013.

42. Barker AT, Jalinous R and Freeston IL: Non-invasive magnetic stimulation of human motor cortex. Lancet 1: 1106-1107, 1985.

43. Uzair M, Abualait T, Arshad M, Yoo WK, Mir A, Bunyan RF and Bashir S: Transcranial magnetic stimulation in animal models of neurodegeneration. Neural Regen Res 17: 251-265, 2022.

44. Perera T, George MS, Grammer G, Janicak PG, Pascual-Leone A and Wirecki TS: The clinical TMS society consensus review and treatment recommendations for TMS therapy for major depressive disorder. Brain Stimul 9: 336-346, 2016.

45. George MS: Transcranial magnetic stimulation for the treatment of depression. Expert Rev Neurother 10: 1761-1772, 2010.

46. Hawken ER, Dilkov D, Kaludiev E, Simek S, Zhang F and Milev R: Transcranial magnetic stimulation of the supplementary motor area in the treatment of obsessive-compulsive disorder: A multi-site study. Int J Mol Sci 17: 420, 2016.

47. Starling AJ, Tepper SJ, Marmura MJ, Shamim EA, Robbins MS, Hindiyeh N, Charles AC, Goadsby PJ, Lipton RB, Silberstein SD, et al: A multicenter, prospective, single arm, open label, observational study of sTMS for migraine prevention (ESPOUSE Study). Cephalalgia 38: 1038-1048, 2018.

48. Moussavi Z, Rutherford G, Lithgow B, Millikin C, Modirrousta M, Mansouri B, Wang X, Omelan C, Fellows L, Fitzgerald $\mathrm{P}$ and Koski L: Repeated transcranial magnetic stimulation for improving cognition in patients with Alzheimer disease: Protocol for a randomized, double-blind, placebo-controlled trial. JMIR Res Protoc 10: e25144, 2021

49. Li X, Qi G, Yu C, Lian G, Zheng H, Wu S, Yuan TF and Zhou D: Cortical plasticity is correlated with cognitive improvement in Alzheimer's disease patients after rTMS treatment. Brain Stimul 14: 503-510, 2021.

50. Mi TM, Garg S, Ba F, Liu AP, Liang PP, Gao LL, Jia Q, Xu EH, Li KC, Chan P and McKeown MJ: Repetitive transcranial magnetic stimulation improves Parkinson's freezing of gait via normalizing brain connectivity. NPJ Parkinsons Dis 6: 16 , 2020.

51. Yang X, Song L and Liu Z: The effect of repetitive transcranial magnetic stimulation on a model rat of Parkinson's disease. Neuroreport 21: 268-272, 2010.

52. Spielberg B: What is the success rate of TMS therapy? 2020.

53. Wagner T, Valero-Cabre A and Pascual-Leone A: Noninvasive human brain stimulation. Annu Rev Biomed Eng 9: 527-65, 2007. 
54. Klomjai W, Katz R and Lackmy-Vallée A: Basic principles of transcranial magnetic stimulation (TMS) and repetitive TMS (rTMS). Ann Phys Rehabil Med 58: 208-213, 2015.

55. Bolognini $\mathrm{N}$ and Ro T: Transcranial magnetic stimulation: Disrupting neural activity to alter and assess brain function. J Neurosci 30: 9647-9650, 2010.

56. Cuypers $\mathrm{K}$ and Marsman A: Transcranial magnetic stimulation and magnetic resonance spectroscopy: Opportunities for a bimodal approach in human neuroscience. Neuroimage 224: 117394, 2021.

57. Chail A, Saini RK, Bhat P, Srivastava K and Chauhan V: Transcranial magnetic stimulation: A review of its evolution and current applications. Ind Psychiatry J 27: 172, 2018.

58. Habib S, Hamid U, Jamil A, Zainab AZ, Yousuf T, Habib S, Tariq SM and Ali F: Transcranial magnetic stimulation as a therapeutic option for neurologic and psychiatric illnesses. Cureus 10: e3456, 2018.

59. Eldaief MC, Press DZ and Pascual-Leone A: Transcranial magnetic stimulation in neurology: A review of established and prospective applications. Neurol Clin Pract 3: 519-526, 2013.

60. Alomar M, Yoo W-K, Vernet M, Murtaza G, Rotenberg A and Bashir S: Human brain connectivity in response to paired pulse TMS paradigm. Brain Stimul 10: 353, 2017.

61. Kim TD, Hong G, Kim J and Yoon S: Cognitive enhancement in neurological and psychiatric disorders using transcranial magnetic stimulation (TMS): A review of modalities, potential mechanisms and future implications. Exp Neurobiol 28: 1-16, 2019.

62. Fried PJ, Jannati A, Davila-Pérez P and Pascual-Leone A: Reproducibility of single-pulse, paired-pulse, and intermittent theta-burst TMS measures in healthy aging, type- 2 diabetes, and Alzheimer's disease. Front Aging Neurosci 9: 263, 2017.

63. Chervyakov AV, Chernyavsky AY, Sinitsyn DO and Piradov MA: Possible mechanisms underlying the therapeutic effects of transcranial magnetic stimulation. Front Hum Neurosci 9: 303, 2015.

64. Agarwal S, Koch G, Hillis AE, Huynh W, Ward NS, Vucic S and Kiernan MC: Interrogating cortical function with transcranial magnetic stimulation: Insights from neurodegenerative disease and stroke. J Neurol Neurosurg Psychiatry 90: 47-57, 2019.

65. Jackson J, Jambrina E, Li J, Marston H, Menzies F, Phillips K and Gilmour G: Targeting the synapse in Alzheimer's disease. Front Neurosci 13: 735, 2019.

66. Wang X, Mao Z, Ling Z and Yu X: Repetitive transcranial magnetic stimulation for cognitive impairment in Alzheimer's disease: A meta-analysis of randomized controlled trials. J Neurol 267: 791-801, 2020.

67. Holczer A, Németh VL, Vékony T, Vécsei L, Klivényi P and Must A: Non-invasive brain stimulation in Alzheimer's disease and mild cognitive impairment-a state-of-the-art review on methodological characteristics and stimulation parameters. Front Hum Neurosci 14: 179, 2020.

68. Guerra A, Assenza F, Bressi F, Scrascia F, Del Duca M, Ursini F, Vollaro S, Trotta L, Tombini M, Chisari C and Ferreri F: Transcranial magnetic stimulation studies in Alzheimer's disease. Int J Alzheimers Dis 2011: 263817, 2011.

69. Yang HY, Liu Y, Xie JC, Liu NN and Tian X: Effects of repetitive transcranial magnetic stimulation on synaptic plasticity and apoptosis in vascular dementia rats. Behav Brain Res 281: $149-155,2015$.

70. Capelli E, Torrisi F, Venturini L, Granato M, Fassina L, Lupo GFD and Ricevuti G: Low-frequency pulsed electromagnetic field is able to modulate miRNAs in an experimental cell model of Alzheimer's disease. J Healthcare Eng 2017: 2530270 , 2017.

71. Xiao N and Le QT: Neurotrophic factors and their potential applications in tissue regeneration. Arch Immunol Ther Exp (Warsz) 64: 89-99, 2016.

72. Sampaio TB, Savall AS, Gutierrez MEZ and Pinton S: Neurotrophic factors in Alzheimer's and Parkinson's diseases: Implications for pathogenesis and therapy. Neural Regen Res 12: 549-557, 2017.

73. Budni J, Bellettini-Santos T, Mina F, Garcez ML and Zugno AI The involvement of BDNF, NGF and GDNF in aging and Alzheimer's disease. Aging Dis 6: 331-341, 2015.

74. Miranda M, Morici JF, Zanoni MB and Bekinschtein P: Brain-derived neurotrophic factor: A key molecule for memory in the healthy and the pathological brain. Front Cell Neurosci 13: 363, 2019.
75. Ballinger EC, Ananth M, Talmage DA and Role LW: Basal forebrain cholinergic circuits and signaling in cognition and cognitive decline. Neuron 91: 1199-1218, 2016.

76. Martinez JL, Zammit MD, West NR, Christian BT and Bhattacharyya A: Basal forebrain cholinergic neurons: Linking down syndrome and Alzheimer's disease. Front Aging Neurosci 13: 703876, 2021

77. Serrano-Pozo A, Frosch MP, Masliah E and Hyman BT: Neuropathological alterations in Alzheimer disease. Cold Spring Harb Perspect Med 1: a006189, 2011.

78. Pang Y and Shi M: Repetitive transcranial magnetic stimulation improves mild cognitive impairment associated with Alzheimer's disease in mice by modulating the miR-567/NEUROD2/PSD95 axis. Neuropsychiatr Dis Treat 17: 2151-2161, 2021.

79. Wang ZH, Xiang J, Liu X, Yu SP, Manfredsson FP, Sandoval IM, Wu S, Wang JZ and Ye K: Deficiency in BDNF/TrkB neurotrophic activity stimulates $\delta$-secretase by upregulating $\mathrm{C} / \mathrm{EBP} \beta$ in Alzheimer's disease. Cell Rep 28: 655-669.e5, 2019.

80. Ng TKS, Ho CSH, Tam WWS, Kua EH and Ho RC: Decreased serum brain-derived neurotrophic factor (BDNF) levels in patients with Alzheimer's disease (AD): A systematic review and meta-analysis. Int J Mol Sci 20: 257, 2019.

81. Chen X, Dong GY and Wang LX: High-frequency transcranial magnetic stimulation protects APP/PS1 mice against Alzheimer's disease progress by reducing APOE and enhancing autophagy. Brain Behavior 10: e01740, 2020.

82. Tan T, Xie J, Liu T, Chen X, Zheng X, Tong Z and Tian X: Low-frequency $(1 \mathrm{~Hz})$ repetitive transcranial magnetic stimulation (rTMS) reverses $A \beta(1-42)$-mediated memory deficits in rats. Exp Gerontol 48: 786-794, 2013.

83. Chen X, Chen S, Liang W and Ba F: Administration of repetitive transcranial magnetic stimulation attenuates $A \beta_{1-42}$-induced Alzheimer's disease in mice by activating $\beta$-catenin signaling. Biomed Res Int 2019: 1431760, 2019.

84. Schaller G, Sperling W, Richter-Schmidinger T, Mühle C, Heberlein A, Maihöfner C, Kornhuber J and Lenz B: Serial repetitive transcranial magnetic stimulation (rTMS) decreases BDNF serum levels in healthy male volunteers. J Neural Transm (Vienna) 121: 307-313, 2014.

85. Gaede G, Hellweg R, Zimmermann H, Brandt AU, Dörr J, Bellmann-Strobl J, Zangen A, Paul F and Pfueller CF: Effects of deep repetitive transcranial magnetic stimulation on brain-derived neurotrophic factor serum concentration in healthy volunteers. Neuropsychobiology 69: 112-119, 2014.

86. Yulug B, Hanoglu L, Khanmammadov E, Duz OA, Polat B, Hanoglu T, Gunal MY and Kilic E: Beyond the therapeutic effect of rTMS in Alzheimer's disease: A possible neuroprotective role of hippocampal BDNF?: A minireview. Mini Rev Med Chem 18: 1479-1485, 2018.

87. Huang WJ, Zhang X and Chen WW: Role of oxidative stress in Alzheimer's disease. Biomed Rep 4: 519-522, 2016.

88. Cheignon C, Tomas M, Bonnefont-Rousselot D, Faller P, Hureau $\mathrm{C}$ and Collin F: Oxidative stress and the amyloid beta peptide in Alzheimer's disease. Redox Biol 14: 450-464, 2018.

89. Chen $\mathrm{Z}$ and Zhong C: Oxidative stress in Alzheimer's disease. Neurosci Bull 30: 271-281, 2014.

90. Perry G, Cash AD and Smith MA: Alzheimer disease and oxidative stress. J Biomed Biotechnol 2: 120-123, 2002.

91. Butterfield DA and Halliwell B: Oxidative stress, dysfunctional glucose metabolism and Alzheimer disease. Nat Rev Neurosci 20: 148-160, 2019.

92. Molinari C, Morsanuto V, Ruga S, Notte F, Farghali M, Galla R and Uberti F: The role of BDNF on aging-modulation markers. Brain Sci 10: 285, 2020.

93. Umeno A, Biju V and Yoshida Y: In vivo ROS production and use of oxidative stress-derived biomarkers to detect the onset of diseases such as Alzheimer's disease, Parkinson's disease, and diabetes. Free Radical Res 51: 413-427, 2017.

94. Durmaz O, Ispir E, Baykan H, Alisik M and Erel Ö: The impact of repetitive transcranial magnetic stimulation on oxidative stress in subjects with medication-resistant depression. J ECT 34: 127-131, 2018.

95. Niimi M, Hashimoto K, Kakuda W, Miyano S, Momosaki R, Ishima T and Abo M: Role of brain-derived neurotrophic factor in beneficial effects of repetitive transcranial magnetic stimulation for upper limb hemiparesis after stroke. PLoS One 11: e0152241, 2016. 
96. Medina-Fernandez FJ, Escribano BM, Agüera E Aguilar-Luque M, Feijoo M, Luque E, Garcia-Maceira FI, Pascual-Leone A, Drucker-Colin R and Tunez I: Effects of transcranial magnetic stimulation on oxidative stress in experimental autoimmune encephalomyelitis. Free Radical Res 51: 460-469, 2017.

97. Snowden SG, Ebshiana AA, Hye A, Pletnikova O, O'Brien R, Yang A, Troncoso J, Legido-Quigley $\mathrm{C}$ and Thambisetty $\mathrm{M}$ : Neurotransmitter imbalance in the brain and Alzheimer's disease pathology. J Alzheimers Dis 72: 35-43, 2019.

98. Svob Strac D, Muck-Seler D and Pivac N: Neurotransmitter measures in the cerebrospinal fluid of patients with Alzheimer's disease: A review. Psychiatr Danub 27: 14-24, 2015.

99. Kaur S, DasGupta G and Singh S: Altered neurochemistry in Alzheimer's disease: Targeting neurotransmitter receptor mechanisms and therapeutic strategy. Neurophysiology 51: 293-309, 2019.

100. Speranza L, di Porzio U, Viggiano D, de Donato A and Volpicelli F: Dopamine: The neuromodulator of long-term synaptic plasticity, reward and movement control. Cells 10 $735,2021$.

101. He Z, Jiang Y, Gu S, Wu D, Feng G, Ma X, Huang JH and Wang F: The aversion function of the limbic dopaminergic neurons and their roles in functional neurological disorders. Front Cell Dev Biol 9: 713762, 2021.

102.Pan X, Kaminga AC, Wen SW, Wu X, Acheampong K and Liu A: Dopamine and dopamine receptors in Alzheimer's disease: A systematic review and network meta-analysis. Front Aging Neurosci 11: 175, 2019.

103. D'Amelio M, Puglisi-Allegra S and Mercuri N: The role of dopaminergic midbrain in Alzheimer's disease: Translating basic science into clinical practice. Pharmacol Res 130: 414-419, 2018.

104. Nobili A, Latagliata EC, Viscomi MT, Cavallucci V, Cutuli D, Giacovazzo G, Krashia P, Rizzo FR, Marino R, Federici $\mathrm{M}$, et al: Dopamine neuronal loss contributes to memory and reward dysfunction in a model of Alzheimer's disease. Nat Commun 8: 14727, 2017.

105. Malik S, Jacobs M, Cho SS, Boileau I, Blumberger D, Heilig M, Wilson A, Daskalakis ZJ, Strafella AP, Zangen A and Le Foll B: Deep TMS of the insula using the H-coil modulates dopamine release: A crossover $\left[{ }^{11} \mathrm{C}\right]$ PHNO-PET pilot trial in healthy humans. Brain Imaging Behav. 12: 1306-1317, 2018.

106. Cho SS and Strafella AP: rTMS of the left dorsolateral prefrontal cortex modulates dopamine release in the ipsilateral anterior cingulate cortex and orbitofrontal cortex. PLoS One 4: e6725, 2009.

107. Liu J, Chang L, Song Y, Li H and Wu Y: The role of NMDA receptors in Alzheimer's disease. Front Neurosci 13: 43, 2019.

108. Zhang Y, Li P, Feng J and Wu M: Dysfunction of NMDA receptors in Alzheimer's disease. Neurol Sci 37: 1039-1047, 2016.

109. Kodis EJ, Choi S, Swanson E, Ferreira G, Bloom GS and Dementia: N-methyl-D-aspartate receptor-mediated calcium influx connects amyloid- $\beta$ oligomers to ectopic neuronal cell cycle reentry in Alzheimer's disease. Alzheimers Dement 14 1302-1312, 2018.

110. Tsang SW, Vinters HV, Cummings JL, Wong PT, Chen CP and Lai MK: Alterations in NMDA receptor subunit densities and ligand binding to glycine recognition sites are associated with chronic anxiety in Alzheimer's disease. Neurobiol. Aging 29: 1524-1532, 2008

111. Battaglia F, Wang HY, Ghilardi MF, Gashi E, Quartarone A, Friedman E and Nixon RA: Cortical plasticity in Alzheimer's disease in humans and rodents. Biol Psychiatry 62: 1405-1412, 2007.

112.Zhang N, Xing M, Wang Y, Tao H and Cheng Y: Repetitive transcranial magnetic stimulation enhances spatial learning and synaptic plasticity via the VEGF and BDNF-NMDAR pathways in a rat model of vascular dementia. Neuroscience 311: 284-291, 2015.

113. Niimi M, Fujita Y, Ishima T, Hashimoto K, Sasaki N, Hara T, Yamada $\mathrm{N}$ and Abo M: Role of D-serine in the beneficial effects of repetitive transcranial magnetic stimulation in post-stroke patients. Acta Neuropsychiatr 32: 1-22, 2020.

114. Chi H, Chang H-Y and Sang TK: Neuronal cell death mechanisms in major neurodegenerative diseases. Int J Mol Sci 19 3082,2018

115. Obulesu M and Lakshmi MJ: Apoptosis in Alzheimer's disease: An understanding of the physiology, pathology and therapeutic avenues. Neurochem Res 39: 2301-2312, 2014.
116. Paradis E, Douillard H, Koutroumanis M, Goodyer $\mathrm{C}$ and LeBlanc A: Amyloid beta peptide of Alzheimer's disease downregulates Bcl-2 and upregulates bax expression in human neurons. J Neurosci 16: 7533-7539, 1996.

117. Guo F, Lou J, Han X, Deng Y and Huang X: Repetitive transcranial magnetic stimulation ameliorates cognitive impairment by enhancing neurogenesis and suppressing apoptosis in the hippocampus in rats with ischemic stroke. Front Physiol 8: 559, 2017.

118. Yulug B, Hanoglu L, Kilic E, Polat B and Rüdiger Schabitz W: The neuroprotective role of repetitive transcranial magnetic stimulation (rTMS) for neurodegenerative diseases: A short review on experimental studies. Mini Rev Med Chem 16: 1269-1273, 2016.

119. Cappa SF, Binetti G, Pezzini A, Padovani A, Rozzini L and Trabucchi M: Object and action naming in Alzheimer's disease and frontotemporal dementia [see comment]. Neurology 50: 351-355, 1998

120. Almor A, Aronoff JM, MacDonald MC, Gonnerman LM, Kempler D, Hintiryan H, Hayes UL, Arunachalam S and Andersen ES: A common mechanism in verb and noun naming deficits in Alzheimer's patients. Brain Lang 111: 8-19, 2009.

121. de Almeida RG, Mobayyen F, Antal C, Kehayia E, Nair VP and Schwartz G: Category-specific verb-semantic deficits in Alzheimer's disease: Evidence from static and dynamic action naming. Cogn Neuropsychol 38: 1-26, 2021.

122. Kumar S, Zomorrodi R, Ghazala Z, Goodman MS, Blumberger DM, Cheam A, Fischer C, Daskalakis ZJ, Mulsant BH, Pollock BG and Rajji TK: Extent of dorsolateral prefrontal cortex plasticity and its association with working memory in patients with Alzheimer disease. JAMA Psychiatry 74: 1266-1274, 2017.

123. Kumar S, Iwata Y, Zomorrodi R, Blumberger DM, Fischer CE Daskalakis ZJ, Mulsant BH, Pollock BG, Graff-Guerrero A and Rajji TK: Dorsolateral prefrontal cortex metabolites and their relationship with plasticity in Alzheimer's disease: Biomarkers (non-neuroimaging)/novel biomarkers. Alzheimers Dement 16: $\mathrm{e} 045879,2020$.

124. Alder G, Signal N, Olsen S and Taylor D: A systematic review of paired associative stimulation (PAS) to modulate lower limb corticomotor excitability: Implications for stimulation parameter selection and experimental design. Front Neurosci 13: 895, 2019.

125. Silverstein J, Cortes M, Tsagaris KZ, Climent A, Gerber LM, Oromendia C, Fonzetti P, Ratan RR, Kitago T, Iacoboni M, et al: Paired associative stimulation as a tool to assess plasticity enhancers in chronic stroke. Front Neurosci 13: 792, 2019.

126. Motta C, Di Lorenzo F, Ponzo V, Pellicciari MC, Bonnì S, Picazio S, Mercuri NB, Caltagirone C, Martorana A and Koch G: Transcranial magnetic stimulation predicts cognitive decline in patients with Alzheimer's disease. J Neurol Neurosurg Psychiatry 89: 1237-1242, 2018.

127. Bashir S, Al-Hussain F, Hamza A, Shareefi GF, Abualait T and Yoo WK: Role of single low pulse intensity of transcranial magnetic stimulation over the frontal cortex for cognitive function. Front Hum Neurosci 14: 205, 2020.

128. Nardone R, Tezzon F, Höller Y, Golaszewski S, Trinka E and Brigo F: Transcranial magnetic stimulation (TMS)/repetitive TMS in mild cognitive impairment and Alzheimer's disease. Acta Neurol Scand 129: 351-366, 2014

129. Cappa SF, Sandrini M, Rossini PM, Sosta K and Miniussi C: The role of the left frontal lobe in action naming rTMS evidence. Neurology 59: 720-723, 2002.

130. Cotelli M, Manenti R, Cappa SF, Geroldi C, Zanetti O, Rossini PM and Miniussi C: Effect of transcranial magnetic stimulation on action naming in patients with Alzheimer disease. Arch Neurol 63: 1602-1604, 2006

131. Cotelli M, Manenti R, Cappa SF, Zanetti O and Miniussi C: Transcranial magnetic stimulation improves naming in Alzheimer disease patients at different stages of cognitive decline. Eur J Neurol 15: 1286-1292, 2008.

132. Cotelli M, Calabria M, Manenti R, Rosini S, Zanetti O, Cappa SF and Miniussi C: Improved language performance in Alzheimer disease following brain stimulation. J Neurol Neurosurg Psychiatry 82: 794-797, 2011.

133. Ahmed MA, Darwish ES, Khedr EM, El Serogy YM and Ali AM: Effects of low versus high frequencies of repetitive transcranial magnetic stimulation on cognitive function and cortical excitability in Alzheimer's dementia. J Neurology 259: 83-92, 2012 
134. Zhang F, Qin Y, Xie L, Zheng C, Huang X and Zhang M: High-frequency repetitive transcranial magnetic stimulation combined with cognitive training improves cognitive function and cortical metabolic ratios in Alzheimer's disease. J Neural Transm (Vienna) 126: 1081-1094, 2019.

135. Turriziani P, Smirni D, Mangano GR, Zappalà G, Giustiniani A Cipolotti L and Oliveri M: Low-frequency repetitive transcranial magnetic stimulation of the right dorsolateral prefrontal cortex enhances recognition Memory in Alzheimer's disease. J Alzheimers Dis 72: 613-622, 2019.

136. Huang Z, Tan T, Du Y, Chen L, Fu M, Yu Y, Zhang L, Song W and Dong Z: Low-frequency repetitive transcranial magnetic stimulation ameliorates cognitive function and synaptic plasticity in APP23/PS45 mouse model of Alzheimer's disease. Front Aging Neurosci 9: 292, 2017.

137. Bagattini C, Zanni M, Barocco F, Caffarra P, Brignani D, Miniussi $C$ and Defanti CA: Enhancing cognitive training effects in Alzheimer's disease: rTMS as an add-on treatment. Brain Stimul 13: 1655-1664, 2020.

138. Huerta PT and Volpe BT: Transcranial magnetic stimulation, synaptic plasticity and network oscillations. J Neuroeng Rehabil 6: 7, 2009.

139. Liu W, Ma R and Yuan Y: Post-transcriptional regulation of genes related to biological behaviors of gastric cancer by long noncoding RNAs and MicroRNAs. J Cancer 8: 4141-4154, 2017.

140. Catalanotto C, Cogoni C and Zardo G: MicroRNA in control of gene expression: An overview of nuclear functions. Int J Mol Sci 17: 1712, 2016.

141. Zhao J, Yue D, Zhou Y, Jia L, Wang H, Guo M, Xu H, Chen C, Zhang $\mathrm{J}$ and $\mathrm{Xu} \mathrm{L}$ : The role of MicroRNAs in $\mathrm{A} \beta$ deposition and Tau phosphorylation in Alzheimer's disease. Front Neurol 8: $342,2017$.

142. Konovalova J, Gerasymchuk D, Parkkinen I, Chmielarz P and Domanskyi A: Interplay between MicroRNAs and oxidative stress in neurodegenerative diseases. Int J Mol Sci 20: 6055, 2019.

143. Friedman RC, Farh KK, Burge CB and Bartel DP: Most mammalian mRNAs are conserved targets of microRNAs. Genome Res 19: 92-105, 2009.

144. Rooda I, Hensen K, Kaselt B, Kasvandik S, Pook M, Kurg A, Salumets A and Velthut-Meikas A: Target prediction and validation of microRNAs expressed from FSHR and aromatase genes in human ovarian granulosa cells. Sci Rep 10: 2300, 2020.

145. Song M: miRNAs-dependent regulation of synapse formation and function. Genes Genomics 42: 837-845, 2020.

146. Hu Z and Li Z: miRNAs in synapse development and synaptic plasticity. Curr Opin Neurobiol 45: 24-31, 2017.

147. Siedlecki-Wullich D, Català-Solsona J, Fábregas C, Hernández I, Clarimon J, Lleó A, Boada M, Saura CA, Rodríguez-Álvarez J and Miñano-Molina AJ: Altered microRNAs related to synaptic function as potential plasma biomarkers for Alzheimer's disease. Alzheimers Res Ther 11: 46, 2019.

148. Wei W, Wang ZY, Ma LN, Zhang TT, Cao Y and Li H MicroRNAs in Alzheimer's disease: Function and potential applications as diagnostic biomarkers. Front Mol Neurosci 13: 160,2020

149. Angelucci F, Cechova K, Valis M, Kuca K, Zhang B and Hort J: MicroRNAs in Alzheimer's disease: Diagnostic markers or therapeutic agents? Front Pharmacol 10: 665, 2019.

150. Amakiri N, Kubosumi A, Tran J and Reddy PH: Amyloid beta and microRNAs in Alzheimer's disease. Front Neurosci 13: 430, 2019.

151. Liu H, Han XH, Chen H, Zheng CX, Yang Y and Huang XL: Repetitive magnetic stimulation promotes neural stem cells proliferation by upregulating MiR-106b in vitro. J Huazhong Univ Sci Technolog Med Sci 35: 766-772, 2015
152. Liu H, Li G, Ma C, Chen Y, Wang J and Yang Y: Repetitive magnetic stimulation promotes the proliferation of neural progenitor cells via modulating the expression of miR-106b. Int J Mol Med 42: 3631-3639, 2018.

153. Aydin-Abidin S, Trippe J, Funke K, Eysel UT and Benali A: High- and low-frequency repetitive transcranial magnetic stimulation differentially activates c-Fos and zif268 protein expression in the rat brain. Exp Brain Res 188: 249-261, 2008.

154. Perez FP, Maloney B, Chopra N, Morisaki JJ and Lahiri DK: Repeated electromagnetic field stimulation lowers amyloid- $\beta$ peptide levels in primary human mixed brain tissue cultures. Sci Rep 11: 621, 2021.

155. Loo CK, McFarquhar TF and Mitchell PB: A review of the safety of repetitive transcranial magnetic stimulation as a clinical treatment for depression. Int J Neuropsychopharmacol 11: 131-147, 2008.

156. Najib U and Horvath J: Transcranial magnetic stimulation (TMS) safety considerations and recommendations. Neuromethods 89: 15-30, 2014.

157. Wassermann EM: Side effects of repetitive transcranial magnetic stimulation. Depress Anxiety 12: 124-129, 2000

158. Dhamne SC, Kothare RS, Yu C, Hsieh TH, Anastasio EM, Oberman L, Pascual-Leone A and Rotenberg A: A measure of acoustic noise generated from transcranial magnetic stimulation coils. Brain Stimul 7: 432-434, 2014.

159. Varone G, Hussain Z, Sheikh Z, Howard A, Boulila W, Mahmud M, Howard N, Morabito FC and Hussain A: Real-time artifacts reduction during TMS-EEG co-registration: A comprehensive review on technologies and procedures. Sensors (Basel) 21: 637, 2021.

160. Duecker F and Sack AT: Rethinking the role of sham TMS Front Psychol 6: 210, 2015

161. Wassermann EM: Risk and safety of repetitive transcranial magnetic stimulation: Report and suggested guidelines from the International Workshop on the Safety of Repetitive Transcranial Magnetic Stimulation, June 5-7, 1996. Electroencephalogr Clin Neurophysiol 108: 1-16, 1998.

162. Chen R, Gerloff C, Classen J, Wassermann EM, Hallett M and Cohen LG: Safety of different inter-train intervals for repetitive transcranial magnetic stimulation and recommendations for safe ranges of stimulation parameters. Electroencephalogr Clin Neurophysiol 105: 415-421, 1997.

163. Rossi S, Hallett M, Rossini PM and Pascual-Leone A; Safety of TMS Consensus Group: Safety, ethical considerations, and application guidelines for the use of transcranial magnetic stimulation in clinical practice and research. Clin Neurophysiol 120: 2008-2039, 2009.

164. DeTure MA and Dickson DW: The neuropathological diagnosis of Alzheimer's disease. Mol Neurodegener 14: 32, 2019.

165. Jellinger KA: Neuropathology of the Alzheimer's continuum: An update. Free Neuropathol 1: 32-32, 2020.

166. Speer AM, Kimbrell TA, Wassermann EM, D Repella J, Willis MW, Herscovitch P and Post RM: Opposite effects of high and low frequency rTMS on regional brain activity in depressed patients. Biol Psychiatry 48: 1133-1141, 2000.

167. Ilmoniemi RJ, Mäki H, Saari J, Salvador R and Miranda PC: The frequency-dependent neuronal length constant in transcranial magnetic stimulation. Front Cell Neurosci 10: 194, 2016.

168. Freedberg M, Reeves JA, Hussain SJ, Zaghloul KA and Wassermann EM: Identifying site- and stimulation-specific TMS-evoked EEG potentials using a quantitative cosine similarity metric. PLoS One 15: e0216185, 2020.

This work is licensed under a Creative Commons Attribution-NonCommercial-NoDerivatives 4.0 International (CC BY-NC-ND 4.0) License. 